FUAD MORAES IBRAHIM

\title{
Miopia como causa de deficiência visual em sujeitos de 10 a 15 anos na cidade de Gurupi-TO
}

Dissertação apresentada à Universidade de São Paulo - Faculdade de Medicina de Ribeirão Preto, para obtenção do Título de Mestre em Ciências Médicas.

RIBEIRÃO PRETO 


\section{Miopia como causa de deficiência visualem sujeitos de 10 a 15 anos na cidade de Gurupi-TO}

Dissertação apresentada ao Departamento de Oftalmologia, Otorrinolaringologia e Cirurgia da Cabeça e Pescoço durante o curso de Pós-Graduação em Oftalmologia e apresentada à Universidade de São Paulo - Faculdade de Medicina de Ribeirão Preto, para obtenção do Título de Mestre em Ciências Médicas.

Área de Concentração: Mecanismos Fisiopatológicos dos Sistemas visual e áudio-vestibular.

Orientador: Prof. Dr. Jayter Silva de Paula 


\section{Miopia como causa de deficiência visualem sujeitos de 10 a 15 anos na cidade de Gurupi-TO}

Presidente da banca: Prof. Dr. Jayter Silva de Paula

Banca Examinadora:

Profa. Dra. Maria de Lurdes Veronense

Profa. Dra. Solange Rios Salomão

Prof. Dr. Jayter Silva de Paula

Aprovado em:

/ I 


\section{Dedicatória}

A Deus, doador da vida e da saúde.

Aos meus pais, pela educação, oportunidades e exemplos.

À minha esposa, pelo amor, auxílio e compreensão.

Ao meu irmão, pelo companheirismo.

Ao meu filho que esta a caminho.

Aos meus amigos, pela vivência.

Aos pacientes, pela confiança. 


\section{Agradecimentos}

À FMRP-USP, pela formação dos ideais.

Ao professor Dr. Jayter de Silva Paula pelo crédito, empenho e disponibilidade a despeito dos 1200 quilômetros que nos separam.

À professora Maria de Lourdes Veronense pelos conselhos e sábios questionamentos.

Ao Professor Eduardo Rocha pelo sorriso e atenção.

À disciplina de oftalmologia da FCM-UNICAMP, pelos ensinos em oftalmologia.

À minha mãe, companheira nas viagens para Ribeirão Preto, pela revisão do texto e sugestões.

À minha esposa Juliana, pelas vezes que ficou só, cuidando de tudo.

Ao meu irmão Marlon, por sempre ir aplanando os caminhos.

Ao amigo Wellington, pelas boas idéias, ajuda na estruturação e preparo dos dados. 


\section{Resumo}

Objetivos: Avaliar a freqüência de miopia como causa de deficiência visual em sujeitos com idade entre 10 a 15 anos residentes na cidade de Gurupi assim como a sua relação com a distribuição com idade e sexo.

Métodos: Estudo transversal populacional. Foram sorteados e avaliados 50 conglomerados dos 59 anteriormente utilizados pelo IBGE para a realização do Censo 2000 compreendendo toda a cidade de Gurupi. Uma equipe treinada visitou as casas seguindo uma ordem de quarteirões definidos previamente pelo IBGE. Foram usados como critérios de inclusão idade de 10 a 15 anos e residir no local por, pelo menos, seis meses. As residências em que não houve resposta foram revisitadas em uma segunda oportunidade. Após explicação do trabalho e o consentimento por escrito de um responsável, com a ajuda deste, foi preenchida uma ficha com os dados do sujeito. Foi avaliada a acuidade visual de cada olho sem correção, separadamente com cinco optotipos impressos de Snellen em linha correspondentes a visão 20/32 da tabela logMAR, a uma distância de 4 metros. Os sujeitos que apresentaram dificuldade de visualizar mais de um optotipo com um ou ambos os olhos foram encaminhados para avaliação em consultório por um oftalmologista. Foi realizado teste de motilidade ocular e revistada a acuidade visual com tabela de logMar retro iluminada a 4 metros. Após cicloplegia, foi feita a auto-refração, seguido da refração subjetiva utilizando tabela logMar, exame externo, biomicroscopia e fundoscopia. Foi prescrita a correção para os sujeitos que apresentaram melhora da acuidade visual após a refração. A deficiência foi classificada em refrativa, catarata, tracoma, ambliopia, alterações retinianas, estrabismo e outros.

Resultados: Foram examinados 1590 sujeitos com idade variando entre 10 a 15 anos, sendo 814 (51\%) do sexo masculino e 776 (49\%) do sexo feminino. Dos 167 que apresentaram limitações para identificar os optotipos de Snellen, 127 (76\%) compareceram para a avaliação em consultório, sendo que 61 (59\%) não necessitaram de correção. Das correções, 15 (22\%) foram corrigidos com lentes com equivalente esférico positivo. As prescrições com equivalente esférico negativo somaram 51 (77\%) com variação entre $-0,5$ até $-7,00$ dioptrias esféricas, correspondendo a uma freqüência de miopia de 3,2\%. Destes, 23 (45\%) eram do sexo masculino e 28 (55\%) do sexo feminino. Dos sujeitos que necessitaram de óculos, nove (10\%) ainda não faziam uso prévio de correção. Os erros refrativos foram a principal causa de deficiência de visão, responsáveis por 53 (80\%) dos casos, sendo 45 (90\%) míopes e oito (10\%) hipermetropes. Em seguida, ambliopia com 8 (12\%) sujeitos, 4 (6\%) com alterações retinianas e 1 (1\%) com catarata congênita. As variáveis sexo, idade, região onde residia, uso prévio de óculos foram associadas com a miopia por regressão multivariada sem nenhuma relação significativa.

Conclusão: Os erros refrativos são a principal causa de baixa de visão na faixa de idade examinada, com destaque para a miopia, que apresentou uma freqüência de 3,2\%. Nenhum dos fatores estudados apresentou relação estatística com a presença de miopia. 


\section{Abstract}

Objective: To evaluate the frequency of visual impairment caused by myopia in subjects from 10 to 15 years old in the city of Gurupi and its relation with some factors studied in this age group.

Methods: Population-based, transversal study. 50 from 59 clusters from Gurupi - TO, previously used by IBGE (2000), were randomized. All subjects from 10 to 15 years old, living in the same place for at least 6 months were included. Vision was tested in each eye, without correction, with five Snelle's optotypes, corresponding to 20/32 in logMar chart, at four meters distance. When the subjects could not see one or more optotypes with one or both eyes, they were referred to an ophthalmological examination. In the physician office, eye motility was tested and visual acuity was retested the with the logMar chart. After cicloplegia, auto refraction was performed, followed by the subjective refraction (using a retroilluminated logMar chart), inspection, biomicroscopy and fundoscopy. Lenses were prescribed after refraction to patients who showed visual acuity improvement. The causes of visual impairment were classified in refractive, cataract, trachoma, ambliopia, retinopathy, strabismus and others.

Results: 1,590 subjects were examined, in which 814 (51\%) were male and 776 (49\%) were female. Among the 167 subjects screened, 127 (76\%) were examined at the physician office and 76 (59\%) did not receive lens prescription. 15 patients (22\%) of those displayed positive spherical equivalent and 51 (77\%) presented with negative spherical equivalent (varying from $-0,5$ to $-7,00 \mathrm{D}$ ), totalizing a frequency of $3.2 \%$. 23 (45\%) myopic patients were male and 28 (55\%) female. Refractive errors were the main cause of visual impairment [53 (80\%); myopia in 45 and hypermetropia in 8), followed by ambliopia (8, $12 \%)$, retinopathies $(4,6 \%)$ and congenital cataract $(1,1 \%)$. Multivariate analysis of the association of the variables gender, age, region, previous ophthalmic examination and previous glasses with myopia did not present significant relation.

Conclusion: Refractive errors were the major cause of visual impairment in this age group (80\%), mainly represented by myopia, with a general frequency of $3.2 \%$. No co-variable studied displayed statistical relation with the presence of myopia. 
Lista de Figuras 
Figura 1. Esquema representando um olho míope. (Nim, 2007). Nesta figura podem ser visualizados, de forma esquemática, os raios de luz adentrando e convergindo para um ponto focal anterior à retina. Durante este trajeto, os raios encontraram as seguintes estruturas em seqüência, córnea, pupila, cristalino e vítreo. 7

Figura 2. Mapa do estado do Tocantins, com destaque para o município de Gurupi. (Wikipédia, 2007)

Figura 3. Foto aérea da cidade de Gurupi, Tocantins. (arquivo pessoal). 17

Figura 4. Foto da entrada principal da cidade de Gurupi - TO (arquivo pessoal). 18

Figura 5. Mapa da cidade de Gurupi, com a divisão dos grupos utilizados para a realização do trabalho de campo.

Figura 6. Distribuição dos indivíduos investigados divididos por sexo segundo cada faixa etária.

Figura 7. Freqüência de miopia em sujeitos do sexo masculino e feminino pela idade. Foram considerados míopes os que apresentaram equivalente esférico menor que -0,50 em pelo menos um dos olhos

Figura 8. Média dos equivalentes esféricos do olho direito pela idade por sexo e idade dos sujeitos examinados no consultório (Acima: sexo masculino; abaixo: sexo feminino). Os desvios padrão são representados pelas barras verticais.

Figura 9. Distribuição do equivalente esférico dos erros refrativos dos olhos direitos dos sujeitos com idade de 10 a 11 anos. Os pontos representam um intervalo de meia dioptria (por exemplo, aqueles com 1 dioptria compreendem os sujeitos com equivalente variando entre 0,75 e 1,25 dioptrias). Os pontos das extremidades representam os sujeitos com $E E<$ ou igual a $-5,00$ e $>$ ou igual a 5,00 ...... 36

Figura 10. Distribuição do equivalente esférico dos erros refrativos dos olhos direitos dos sujeitos com idade 12 a 13 anos. Os pontos representam um intervalo de meia dioptria (por exemplo, aqueles com 1 dioptria compreendem os sujeitos com equivalente variando entre 0,75 e 1,25 dioptrias). Os pontos das extremidades representam os sujeitos com $\mathrm{EE}<\mathrm{ou}$ igual a $-5,00$ e $>$ ou igual a 5,00 .. 36

Figura 11. Distribuição do equivalente esférico dos erros refrativos dos olhos direitos dos sujeitos com idade de 14 a 15 anos. Os pontos representam um intervalo de meia dioptria (por exemplo, aqueles com 1 dioptria compreendem os sujeitos com equivalente variando entre 0,75 e 1,25 dioptrias). Os pontos das extremidades representam os sujeitos com $\mathrm{EE}<$ ou igual a $-5,00$ e $>$ ou igual a 5,00 
Lista de Tabelas 
Tabela 1. Prevalência de miopia em diversos países. Com data, título, local do estudo, número de sujeitos, faixa de idade e a prevalência.

Tabela 2. Prevalência de miopia em adolescentes no Brasil segundo trabalhos anteriores. Com data, título, local do estudo, número de sujeitos, faixa de idade e a prevalência.

Tabela 3. Freqüência das variáveis em estudos, com o odds ratio bruto e ajustado, considerando a variável miopia. Todas as comparações não alcançaram significância estatística $(p>0,05)$. 38

Tabela 4. Causas de deficiência de visão. 39

Tabela 5. Distribuição do astigmatismo dos sujeitos examinados no consultório. 55 


\section{Lista de Abreviaturas e Símbolos}


Porcentagem

AV

Acuidade visual

DE

Dioptrias esféricas

DP

Desvio padrão

Et al.

et aliae (e outros)

FMRP

Faculdade de Medicina de Ribeirão Preto

IBGE

Instituto Brasileiro de Geografia e Estatística

IC

Intervalo de confiança

LASIK

Do idioma inglês laser in situ keratomileusis - ceratomileses com laser in situ

m

Metros

$\mathrm{N}$

Número de indivíduos

OD

Do idioma inglês Odd Ratio - Razão de chance

OMS

Organização Mundial de Saúde

$p$

p-valor

PRK

Do idioma inglês photorefrative keratomy - Ceratectomia fotorefrativa

RESC

Do idioma inglês Refractive Error Study in Children - Estudo de erros refrativos em crianças

REWG

Do idioma inglês Refractive Error Working Group - Grupo de trabalho de erros refrativos

RK

Do idioma inglês Radial Keratotomy - Ceratotomia radial

SD

Do idioma inglês Standard Deviation - Desvio padrão 
Sumário 


\section{Sumário}

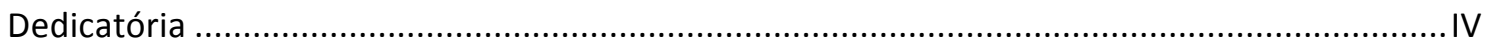

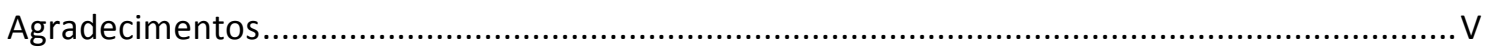

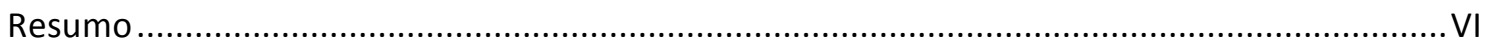

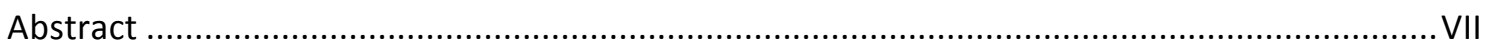

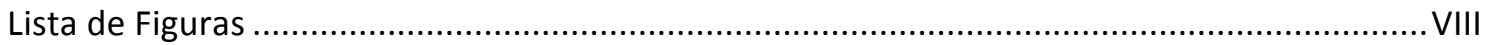

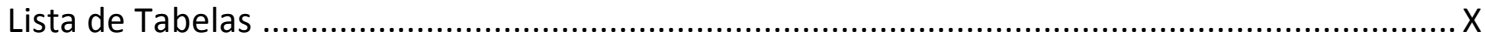

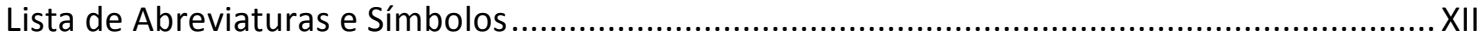

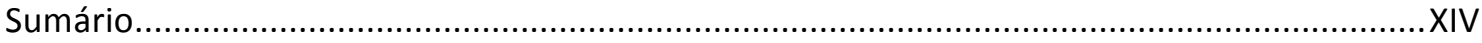

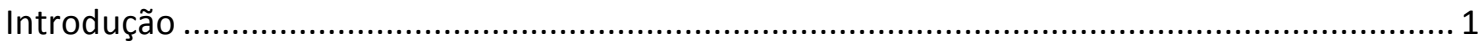

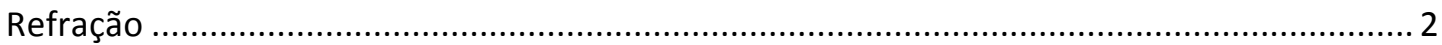

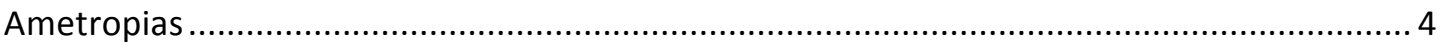

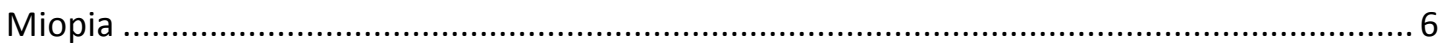

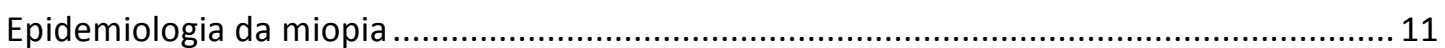

Gurupi..................................................................................................... 15

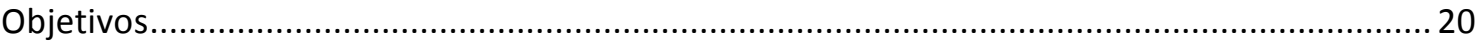

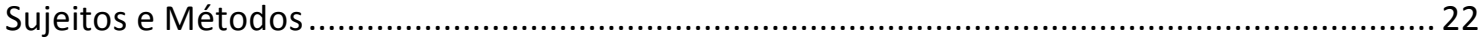

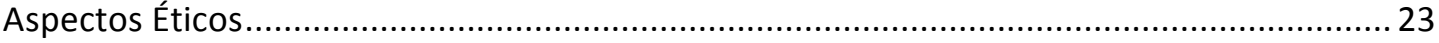

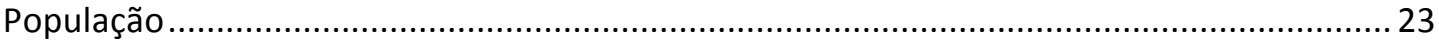

Desenho do Estudo e Seleção dos Pacientes ......................................................... 24

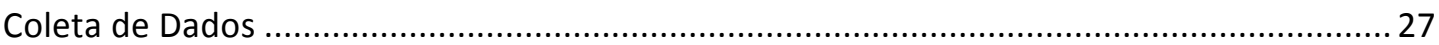

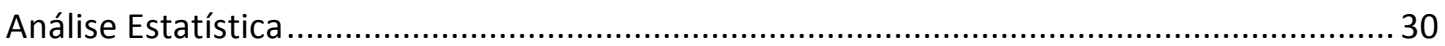

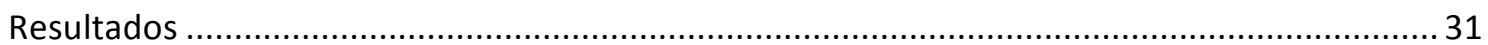

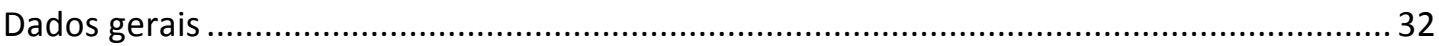

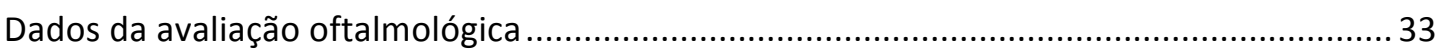

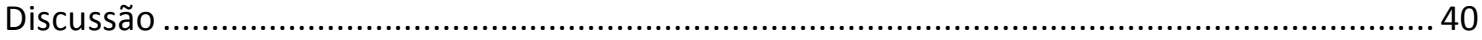

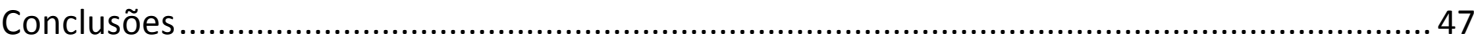

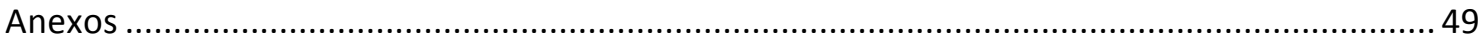

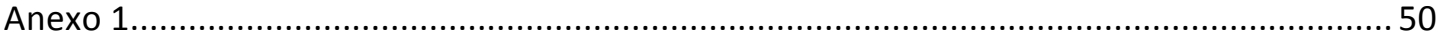

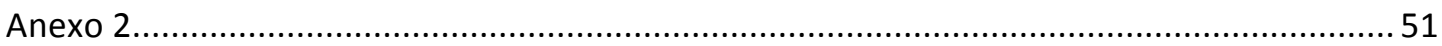

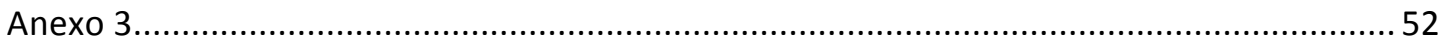

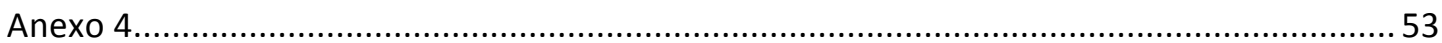

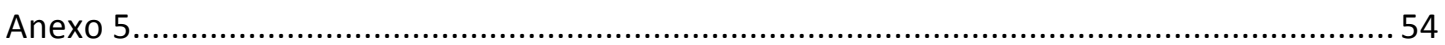

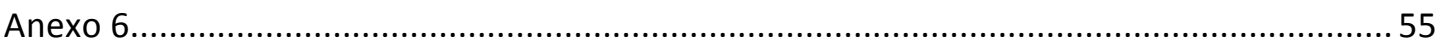




\section{Introdução}


A visão é um dos principais sentidos usados pelos animais na interação com o ambiente. A restrição visual na espécie humana é, sabidamente, um fator que pode limitar a sua participação e desempenho nas diversas atividades cotidianas. Dentre as causas conhecidas de limitação visual, os erros de refração possuem papel primordial, a despeito de poderem ser facilmente tratados, na maioria das vezes. Nos países em desenvolvimento, porém, grande parte destes sujeitos não tem acesso ao tratamento - os óculos.

\section{Refração}

Estudos recentes da física moderna questionam o conceito de que a luz percorre o espaço em linha reta. Porém, para estudos ópticos macroscópicos, esta definição pode ser aceita. Ao atingir a superfície de um meio material, a energia, de maneira genérica, e a luz, em particular, apresentam, sempre, diferentes tipos de interação, dos quais, eventualmente, predomina um deles. Nesses casos, o material é classificado como opaco ou absorvente (quando retém a energia, não a deixando passar), transparente ou translúcido (quando é por ela atravessado), espelhante ou difusor (quando a rechaça para o meio de onde provém). (Bicas, 2005)

A refração, por definição seria o fenômeno de superfície, pelo qual a energia radiante a atravessa, passando ao outro meio. Diferente da absorção, em que a energia radiante se dispersa na intimidade da matéria, na refração ela se mantém com suas características de radiação, embora mude a velocidade de propagação. De fato, a velocidade de propagação de uma dada forma de energia é específica para cada meio material, chegando a servir como um seu identificador: o índice de refração deste 
material. (Bicas, 1991) Em função da resistência encontrada ao atravessar um objeto, a luz sofre uma redução de sua velocidade de $300.000 \mathrm{~km} / \mathrm{h}$.

Com base nisto foram definidos alguns conceitos importantes para a compreensão do estudo da luz.

- Propagação retilínea: nos meios transparentes e homogêneos, a luz se propaga em linha reta

- Princípio da independência: cada raio de luz se estende, independentemente, de qualquer outro.

- Princípio da irreversibilidade: a forma do raio de luz independe do sentido de propagação da luz.

A refração é matematicamente determinada por uma única lei, a partir da qual derivam todas as demais conseqüências, em função das curvaturas das superfícies atravessadas. A lei genérica da refração é conhecida como lei de Snell - Descartes:

$$
n_{i} \cdot \operatorname{sen} i=n_{r} \cdot \operatorname{sen} r
$$

em que $n_{i}$ e $n_{r}$ são os índices de refração dos meios de onde provem a luz (incidência, $n_{i}$ ) e para onde ela segue (refração, $n_{r}$ ), i e r sendo os ângulos de incidência e refração, isto é, as inclinações que a direção de propagação da energia radiante faz com a normal a superfície nos meios de incidência (i) e refração (r), respectivamente. (Bicas, 2005)

Elege-se como unidade óptica a dioptria, tomada como o inverso de uma distância, dada em metros. Assim, por exemplo, um metro equivale a uma dioptria, 
dois metros equivalem a 0,5 dioptrias. Uma lente com distância focal $25 \mathrm{~cm}$ corresponderá a quatro dioptrias; se convergente, tendo, pois focos reais, é designada convencionalmente como positiva $(+4,00 \mathrm{D})$; se for divergente tendo, tendo, então, focos virtuais, será sinalizada como negativa (-4,00 D). (Bicas, 1991)

\section{Ametropias}

O olho é o órgão responsável pelo sentido da visão. Para se compreender o mecanismo de formação da imagem e o comportamento dos raios luminosos no seu caminho até a retina, faz-se necessário o estudo dos diversos elementos que interferem no seu trajeto. Estes elementos são: superfície anterior da córnea, a substância da córnea, a superfície posterior da córnea, o humor aquoso, a superfície anterior do cristalino, a substância do cristalino, a superfície posterior do cristalino e o humor vítreo. Do ponto de vista prático, em apenas duas destas superfícies teremos refração significativa: na superfície anterior da córnea, principalmente, e no cristalino. (Duke-Elder`S, 1997)

É considerado emetropia quando, em um olho em estado de repouso, os raios paralelos que chegam são refratados para convergirem perfeitamente sobre a retina. Quando isto não ocorre, surgem os erros refrativos - ametropias. 


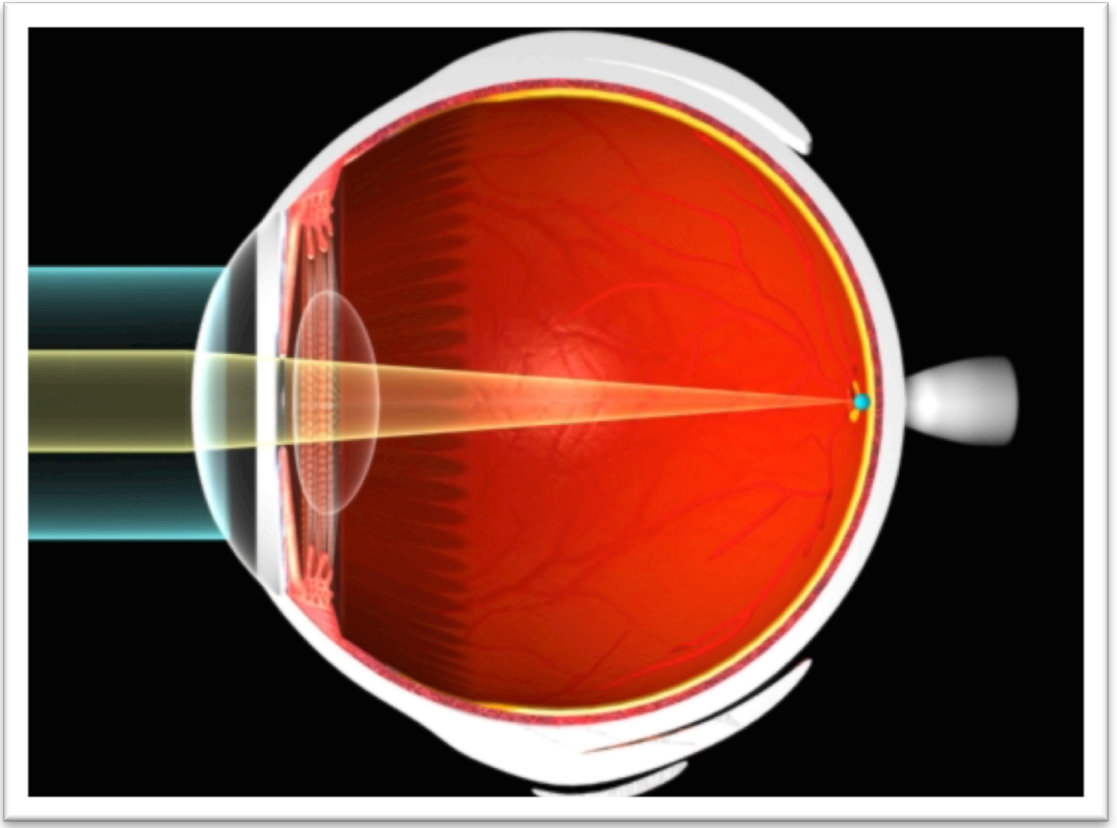

Figura 1. Esquema representando um olho emétrope. Os raios de luz paralelos quando adentram ao olho, formam foco único sobra a mácula. Durante este trajeto, os raios encontraram as seguintes estruturas em seqüência, córnea, pupila, cristalino e vítreo. (Visioncenter, 2008)

Podem ser classificadas em três principais: quando o foco é formado em uma região posterior à retina ocorre a hipermetropia; a miopia ocorre quando a imagem é formada anterior à retina e quando não é formado um foco definido, em função da multiplicidades destes, ocorre o astigmatismo. Estas situações podem ser decorrentes de alteração da posição dos elementos do sistema, como variação do diâmetro ânteroposterior e poder de convergência. As anomalias na superfície da córnea de refração e/ou cristalino também podem ocasionar erros refrativos. (Albuquerque, 2005)

Os erros refrativos são, segundo a Organização Mundial de Saúde (OMS), a principal causa de deficiência de visão tratável no mundo. (Who, 2007) A insuficiência visual devido a anomalias da refração não corrigidas ou insuficientemente corrigidas (VA<6/18 em adultos, <6/12 em crianças), afeta cerca de 200-250 milhões de pessoas. A presbiopia afetará virtualmente todas as pessoas com mais de 45 anos de idade, ou 
seja, 23\% da população mundial. (Vision2020, 2008) Portanto, as ametropias têm uma grande importância, já que são responsáveis pelo prejuízo visual passível de correção em milhões de pessoas em todo o planeta.

Praticamente todos os indivíduos ao nascer são hipermétropes; ao evoluir de acordo com o crescimento do corpo, o eixo ântero-posterior alonga-se e na adolescência atingirá teoricamente a emetropia. Em um olho normal, a contração do músculo ciliar durante a acomodação gera um aumento do poder refrativo do cristalino e, com isto, grande parte da hipermetropia é corrigida (Duke-Elder'S, 1997; Kara-Jose, 2006). Assim, os sujeitos com hipermetropia podem viver sem limitações, independente do uso de correção. E, geralmente, estes indivíduos sofrerão um processo de redução culminando com a idade adulta com a emetropia. (Duke-Elder'S, 1997)

Trabalhos com sujeitos com idade variando de cinco a quinze anos de idade de diversas partes do mundo também confirmam este dado, principalmente pelo aparecimento de miopia nessa faixa etária como pode ser vista na tabela 1. (Junghans e Crewther, 2003; El-Bayoumy, Saad et al., 2007; Gilbert e Ellwein, 2008)

\section{Miopia}

Conhecida popularmente como "vista curta", a miopia (do grego: 'que fecha o olho') é o erro refrativo que ocorre quando os raios que sofreram refração convergem para um ponto anterior à retina na situação de repouso. A miopia ocorre numa série de afecções, as quais se dão por dois mecanismos: o aumento de comprimento axial e/ou e curvatura do globo ocular. A causa mais freqüentemente observada é o 
aumento do diâmetro ântero-posterior do globo ocular, conhecida como miopia axional. Nos casos de miopia de curvatura, ocorre um aumento da curvatura da córnea e/ou cristalino. Também pode acontecer variação no índice de refração, principalmente do cristalino, acarretando a miopia de índice.

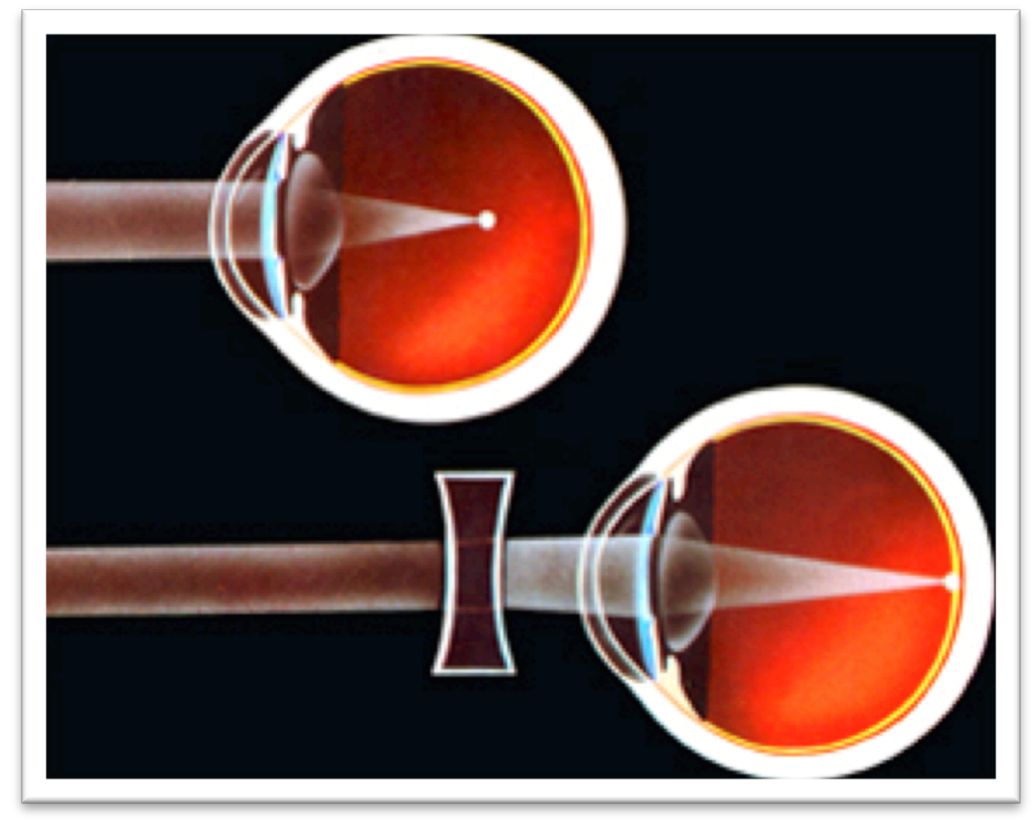

Figura 2. Esquema representando um olho míope . No primeiro esquema podem ser visualizados, de forma esquemática, os raios de luz adentrando e convergindo para um ponto focal anterior à retina. Durante este trajeto, os raios encontraram as seguintes estruturas em seqüência, córnea, pupila, cristalino e vítreo. No olho esquemático abaixo é representado o comportamento do feixe luminoso após a interferência da lente corretora. (Visioncenter, 2008)

Vários fatores já foram arrolados como sendo responsáveis pela miopia, como hereditariedade (Mutti, Mitchell et al., 2002; Mutti, Cooper et al., 2007), uso da visão para atividades próximas (Junghans e Crewther, 2003; El-Bayoumy, Saad et al., 2007), leitura em ambientes com pouca iluminação (Loman, Quinn et al., 2002).

É sabido que a prole de pais míopes tem uma maior chance de também apresentarem miopia. (Wallman, 1994; Mutti, Mitchell et al., 2002) A investigação desta relação e a possibilidade da hereditariedade já é investigada há muito tempo. 
(Cernea, Constantin et al., 1973). Porém, atualmente o conhecimento sobre a genética da miopia evoluiu ao ponto de se investigar a sua relação com genes específicos. (Farbrother, Kirov et al., 2004)

O uso da visão para perto por longos períodos e de forma descontinuada foi analisado como sendo uma possível causa para a miopia. Foi demonstrado que a freqüência e o tempo gastos em atividades próximas com leitura podem estar relacionados com a miopia. (Ip, Saw et al., 2008) Por outro lado, sujeitos que realizam atividades em ambientes externos apresentaram uma prevalência reduzida de miopia. (Rose, Morgan, Ip et al., 2008; Rose, Morgan, Smith et al., 2008)

Alguns estudos foram realizados com sujeitos que desempenham funções que exigem este tipo de visão, como microscopistas e operadores de computador, controladores de textura de tecidos (Mutti, Mitchell et al., 2002; Goldschmidt, 2003; Ip, Saw et al., 2008; Rose, Morgan, Smith et al., 2008).

A miopia pode ser classificada em dois tipos clínicos básicos, com evolução distinta. Em um tipo, mais freqüente, geralmente são encontrados graus mais baixos e sem alterações significativas no exame oftalmológico. Neste caso, a miopia tende a se estabilizar na idade adulta ("late onset myopia"). Já nos casos chamados de miopia patológica, a progressão do grau se mantém mesmo após a idade adulta. (DukeElder`S, 1997; Junghans e Crewther, 2003; El-Bayoumy, Saad et al., 2007)

A principal queixa de um míope é a falta de nitidez para objetos distantes. Por outro lado, os míopes apresentam em grande parte das vezes, uma visão satisfatória para perto. Vale recordar que quanto maior a miopia, menor a distância focal, sendo 
assim necessária uma maior aproximação dos objetos que se busca visualizar com nitidez.

Uma situação curiosa ocorre com pacientes míopes com mais de quarenta anos em função da presbiopia. Os pacientes que apresentam até três dioptrias negativas de correção conseguem realizar atividades próximas sem problemas, desde que não utilizem a correção usual. Como o foco da imagem no infinito ocorre antes da retina nos míopes, quando o objeto é aproximado, a imagem se desloca posteriormente, acabando por atingir o local ideal para a visualização deste, compensando a limitação causada pela redução da acomodação.

$\mathrm{Na}$ miopia patológica, o exame oftalmológico apresenta alterações características como crescente miópico, distúrbios na mácula, estafiloma e alterações da coróide. Estudos têm demonstrado que em algumas populações, principalmente asiáticas, está ocorrendo um aumento da prevalência da miopia entre os sujeitos mais jovens. (Kawuma e Mayeku, 2002; Khandekar, Kurup et al., 2007)

Como opções de tratamento existem lentes corretoras que podem ser utilizadas em armações ou em contato direto com o olho conhecidas como lentes de contato. Existem algumas especulações sobre a possibilidade do uso de lentes de contato interferir em longo prazo na progressão da miopia, porém sem muitas conclusões definitivas. (Heng e Khoo, 1994) Outra possibilidade é o tratamento cirúrgico que busca uma correção de forma contínua e duradoura. Dentre as diferentes abordagens cirúrgicas, a alteração da curvatura externa corneana com o intuito de se alterar o comportamento dos raios luminosos, quando refratados, é a forma mais aceita. Esta intervenção pode ser realizada por meio de técnicas 
diversas como, por exemplo, ceratotomia radial (RK), ceratectomia fotorefrativa (PRK) e ceratomileses com laser In situ. (LASIK). (Krachmer, 2005)

A RK consiste em se realizar incisões radiais na córnea que atingem até a porção média do estroma criando uma nova curvatura corneana. Ela foi utilizada em grande escala há cerca de duas décadas atrás. (Krachmer, 2005) Atualmente se encontra praticamente em desuso em função das aberrações causadas pela não uniformidade da alteração na curvatura e pelo seu aplanamento central pronunciado que se torna mais evidente transcorrida a primeira década após a cirurgia. Assim, estes pacientes apresentavam uma boa qualidade de visão a curto e médio prazo, porém grande parte deles evoluiu com uma deterioração visual tardia e de difícil correção. Isto porque a curvatura corneana se torna muito irregular e com uma região central deveras plana. Este aplanamento leva a astigmatismos elevados que, em grande parte das vezes, não são corrigidos de forma satisfatória com o uso de óculos. Uma possibilidade de tratamento seria o uso de lentes de contato, preferencialmente as rígidas, uma vez que estas poderiam interferir de certa forma na curvatura corneana.

A forma de correção cirúrgica para miopia mais usada atualmente é a ablação corneana por laser. Esta técnica apresenta algumas variações, que apresentam vantagens e limitações dependendo da indicação cirúrgica. A primeira delas é a PRK que remove o epitélio da córnea e o laser é aplicado sobre a porção exposta. Outra técnica disponível é a LASIK. Tal técnica consiste em se realizar um retalho pediculado com um microcerátomo que é rebatido para que o laser possa ser aplicado sobre o leito aberto. Após o procedimento, o retalho é devolvido a sua posição original. (Krachmer, 2005) 
Outra opção de tratamento cirúrgico é o implante de lentes intra-oculares que podem ser utilizadas com ou sem a remoção cirúrgica do cristalino. (Donoso e Castillo, 2006) Esta técnica geralmente é indicada em casos selecionados já que o seu risco é mais elevado uma vez implica em uma cirurgia intra-ocular. O seu resultado também é mais imprevisível que as cirurgias corneanas já que está envolvida uma quantidade maior de variáveis que podem apresentar respostas distintas das esperadas.

\section{Epidemiologia da miopia}

Vários trabalhos já foram realizados para se quantificar os erros refrativos nas mais diversas populações e abordando praticamente todas as faixas etárias. (Murthy, Gupta et al., 2002; Junghans e Crewther, 2003; Naidoo, Raghunandan et al., 2003; Garcia, Orefice et al., 2005; Muszynska-Lachota, Czepita et al., 2005; El-Bayoumy, Saad et al., 2007) Quando comparada a prevalência de miopia em escolares de diversas partes do mundo, como pode ser visto no quadro 1, existe uma grande variação entre as diversas populações. Os povos asiáticos apresentam uma prevalência significativamente mais elevada, por volta de 40\% (Zhao, Pan et al., 2000; Fan, Lam et al., 2004; He, Huang et al., 2007), enquanto que os povos americanos apresentam valores inferiores a 20\% de prevalência (Maul, Barroso et al., 2000; Villarreal, Ohlsson et al., 2003; Garcia, Orefice et al., 2005), semelhante aos residentes no continente africano (Naidoo, Raghunandan et al., 2003; Chuka-Okosa, 2005; Khader, Batayha et al., 2006). 


\begin{tabular}{llllll}
\hline Ano & Titulo & Local & $\mathrm{N}$ & Idade & Miopia \% \\
\hline 2.000 & $\begin{array}{l}\text { Prevalence of myopia in a sample of Greek students. } \\
\text { (Mavracanas, Mandalos et al., 2000) }\end{array}$ & Grécia & 1.738 & $15-18$ & 36,8 \\
2.000 & $\begin{array}{l}\text { Myopisation: The refractive tendency in teenagers. Prevalence of } \\
\text { myopia among young teenagers in Sweden. (Villarreal, Ohlsson }\end{array}$ & $\begin{array}{l}\text { Goteborg, } \\
\text { Suécia }\end{array}$ & 1.045 & $12-13$ & 39,0
\end{tabular}

et al., 2000)

\begin{tabular}{|c|c|c|c|c|c|}
\hline 2.000 & $\begin{array}{l}\text { Refractive Error Study in Children: Results From Shunyi District, } \\
\text { China.(Zhao, Pan et al., 2000) * }\end{array}$ & Bejing, China & 4.884 & $5-15$ & 55.0 \\
\hline 2.000 & $\begin{array}{l}\text { Refractive Error Study in Children: Results From La Florida, Chile. } \\
\text { (Maul, Barroso et al., 2000) * }\end{array}$ & $\begin{array}{l}\text { Santiago, } \\
\text { Chile }\end{array}$ & 5.303 & $5-15$ & 14,3 \\
\hline 2.000 & $\begin{array}{l}\text { Refractive Error Study in Children: Results From Mechi Zone, } \\
\text { Nepal. (Pokharel, Negrel et al., 2000) * }\end{array}$ & Mechi, Nepal & 5.067 & $5-15$ & 1.2 \\
\hline 2.002 & $\begin{array}{l}\text { Referral rates for a functional vision screening among a large } \\
\text { cosmopolitan sample of Australian children. (Junghans, Kiely et } \\
\text { al., 2002) }\end{array}$ & Australia & 2.697 & $3-12$ & 5,3 \\
\hline 2.002 & $\begin{array}{l}\text { Refractive Error in Children in an Urban Population in New Delhi. } \\
\text { (Murthy, Gupta et al., 2002)* }\end{array}$ & $\begin{array}{l}\text { Nova Delhi, } \\
\text { India }\end{array}$ & 6.647 & $5-15$ & 7,4 \\
\hline 2.002 & $\begin{array}{l}\text { Refractive Error in Children in a Rural Population in India. } \\
\text { (Dandona, Dandona et al., 2002) * }\end{array}$ & $\begin{array}{l}\text { Zona rural, } \\
\text { India }\end{array}$ & 4.074 & $7-15$ & 4,1 \\
\hline 2.002 & $\begin{array}{l}\text { Myopia in secondary school students in Mwanza City, Tanzania: } \\
\text { the need for a national screening program. (Wedner, Ross et al., } \\
2002)^{*}\end{array}$ & $\begin{array}{l}\text { Mawanza, } \\
\text { Tanzania }\end{array}$ & 2.511 & $11-27$ & 5,6 \\
\hline 2.002 & $\begin{array}{l}\text { Épidémiologie des erreurs réfractive chez des enfants scolarisés, } \\
\text { socio-économiquement défavorisés en Tunisie. (Ayed, Sokkah et } \\
\text { al., 2002) }\end{array}$ & Tunis, Tunisia & 708 & $6-20$ & 9,1 \\
\hline
\end{tabular}

\begin{tabular}{|c|c|c|c|c|c|}
\hline 2.003 & $\begin{array}{l}\text { Refractive Error and Visual Impairment in African Children in } \\
\text { South Africa. (Naidoo, Raghunandan et al., 2003) * }\end{array}$ & $\begin{array}{l}\text { Durban, Africa } \\
\text { do Sul }\end{array}$ & 4.890 & $5-15$ & 4,0 \\
\hline 2.004 & $\begin{array}{l}\text { Prevalence, Incidence, and Progression of Myopia of School } \\
\text { Children in Hong Kong (Fan, Lam et al., 2004) * }\end{array}$ & Hong Kong & 5.576 & $5-16$ & 37,1 \\
\hline
\end{tabular}

\begin{tabular}{|c|c|c|c|c|c|}
\hline 2.005 & $\begin{array}{l}\text { Refractive Error and Visual Impairment in School-Age Children in } \\
\text { Gombak District, Malaysia (Goh, Abqariyah et al., 2005) }\end{array}$ & $\begin{array}{l}\text { Gombak, } \\
\text { Malasia }\end{array}$ & 4.634 & $7-15$ & 20.7 \\
\hline 2.005 & $\begin{array}{l}\text { Refractive Error and Patterns of Spectacle Use in 12-Year-Old } \\
\text { Australian Children (Robaei, Rose et al., 2005) * }\end{array}$ & $\begin{array}{l}\text { Sidney, } \\
\text { Australia }\end{array}$ & 2.367 & 12 & 12,8 \\
\hline
\end{tabular}




\begin{tabular}{|c|c|c|c|c|c|}
\hline 2.007 & $\begin{array}{l}\text { The prevalence of refractive errors among schoolchildren in } \\
\text { Dezful, Iran. (Fotouhi, Hashemi et al., 2007) * }\end{array}$ & Deszful, Irã & 5.721 & $7-15$ & 3,4 \\
\hline 2.007 & $\begin{array}{l}\text { Refractive Error and Visual Impairment in School Children in } \\
\text { Rural Southern China (He, Huang et al., 2007) * }\end{array}$ & Yangxi, China & 2.454 & 13 & 36,8 \\
\hline 2.007 & $\begin{array}{l}\text { Refractive Error and Visual Impairment in School Children in } \\
\text { Rural Southern China. (He, Huang et al., 2007) * }\end{array}$ & $\begin{array}{l}\text { Guang-zhou, } \\
\text { China }\end{array}$ & 4.364 & $5-15$ & 38,1 \\
\hline
\end{tabular}

*Estudos realizados com base populacional.

Com relação ao Brasil, os trabalhos devidamente publicados abordam faixas etárias distintas e com valores não muito concordantes como pode ser visto na tabela 2. Grande parte destes surgiu após a iniciativa de se fazer um levantamento da visão de escolares. As primeiras investigações remontam para a década de quarenta, quando foram criados os primeiros esforços no sentido de se identificar escolares com limitações visuais. (Conde, 1940) Foram realizados vários esforços em diversas partes do Brasil neste sentido. Destes, podemos destacar a criação do Núcleo de Prevenção a Cegueira da Universidade de Campinas (Kara-Jose, 1982) que foi um dos principais responsáveis pelas ações que, em conjunto com o Conselho Brasileiro de Oftalmologia, Ministério da Saúde e o Ministério da Educação culminaram com projetos de alcance nacional. (Kara-Jose, 2006)

Tabela 2. Prevalência de miopia em adolescentes no Brasil segundo trabalhos anteriores. Com data, título, local do estudo, número de sujeitos, faixa de idade e a prevalência.

\begin{tabular}{|c|c|c|c|c|c|}
\hline Ano & Titulo & Local & $\mathbf{N}$ & Idade & $\begin{array}{l}\text { Miopia } \\
\%\end{array}$ \\
\hline 1.985 & Vícios de refração em escolares do DF. (Hatakeyama, 1985) & Brasília, DF & 4.767 & $7-10$ & 5,9 \\
\hline 1.997 & $\begin{array}{l}\text { Alterações oculares em pessoas carentes do Recife, PE. } \\
\text { (Ventura, 1997) }\end{array}$ & Recife, PE & 672 & $6-18$ & 5,1 \\
\hline 1.997 & $\begin{array}{l}\text { Prevalência de alterações oculares em escolares da zona sul } \\
\text { de São Paulo, SP (Firmo, 1997) }\end{array}$ & $\begin{array}{l}\text { São Paulo, } \\
\text { SP }\end{array}$ & 2.256 & $6-17$ & 3,17 \\
\hline
\end{tabular}




\begin{tabular}{|c|c|c|c|c|c|}
\hline 1.998 & Veja bem Brasil. (Kara-Jose, 2006) & Brasil & 59.193 & 7 & 7,4 \\
\hline 1.999 & Resultados da "Campanha Olho no Olho". (Kara-Jose, 2006) & Brasil & 142.786 & 7 & 13,5 \\
\hline 2.001 & $\begin{array}{l}\text { Prevalência de ametropias em escolares em Ibiporã, PR. } \\
\text { (Schimiti, 2001) }\end{array}$ & Ibiporã, PR & 1.966 & $6-12$ & 10,4 \\
\hline 2.005 & $\begin{array}{l}\text { Prevalência dos erros refrativos em estudantes do nordeste. } \\
\text { (Garcia, Orefice et al., 2005) }\end{array}$ & Natal, RN & 1.024 & $10-15$ & 13,2 \\
\hline 2.005 & $\begin{array}{l}\text { Prevalência dos erros refrativos em estudantes do nordeste. } \\
\text { (Garcia, Orefice et al., 2005) }\end{array}$ & Natal, RN & 1.024 & $10-15$ & 13,2 \\
\hline 2.007 & $\begin{array}{l}\text { Prevalência de erros refrativos em escolares da primeira } \\
\text { série do ensino fundamental da região Nordeste do Rio } \\
\text { Grande do Sul. (Estaica, 2007) }\end{array}$ & $\begin{array}{l}\text { Passo } \\
\text { Fundo, RS }\end{array}$ & 1.608 & 7 & 10 \\
\hline
\end{tabular}

A grande maioria dos trabalhos realizados no Brasil se vale dos escolares para estas aferições. Isto tem a limitação de não necessariamente representar toda a população da localidade. Para o estudo com base em toda a população, por amostragem, a coleta de dados e a análise se tornam mais complexos, tornando, assim, esta metodologia mais dispendiosa e de difícil realização.

Os dados obtidos nos diversos trabalhos apresentam limitações de comparação, uma vez que esses, quase sempre, apresentam particularidades em sua concepção e execução. Além disto, os trabalhos mencionados não são estudos com base populacional, já que ainda não foram publicados estudos epidemiológicos com este desenho sobre erros refrativos referentes a crianças/escolares realizados no Brasil.

Com o intuito de se criar um protocolo de referência neste tema, foi proposto pela OMS a realização dos "Refractive Error Study in Children" (RESC). Os RESCs são estudo com um número elevado de sujeitos avaliados em áreas distintas do planeta 
usando um mesmo padrão metodológico. (Negrel, Maul et al., 2000). Tal padrão consiste em um estudo transversal por amostragem de uma população de indivíduos residentes em uma região, com idade variando entre 5 a 15 anos e a identificação das causas da baixa de visão. Esta faixa de idade compreende uma população que quando apresenta erros refrativos não corrigidos, podem apresentar repercussão na sua vida escolar e na sua futura formação como indivíduo. (Kara-Jose, 2006) Um estudo nos moldes do RESC já foi desenvolvido no Brasil, na cidade de São Paulo, já em fase de publicação. (Salomao, 2008)

Visando facilitar a execução destes trabalhos, o Grupo de Trabalho nos Erros Refrativos (Refractive Error Working Group - REWG) da OMS, propôs mudanças no RESC, visando facilitar a sua execução, sem prejuízo na qualidade e confiabilidade das informações obtidas. (Group, 2002). Outras modificações posteriores foram sugeridas neste mesmo sentido, como cicloplegiar somente os sujeitos que tivessem algum grau de deficiência na acuidade visual para longe. (Salomao, 2008)

\section{Gurupi}

Gurupi é a principal cidade do sul do estado do Tocantins. Sua história está intimamente ligada a construção da rodovia federal BR-153, conhecida como Belém Brasília. Consta que o fundador da cidade, Benjamim Rodrigues chegou a procurar o engenheiro responsável pela rodovia, Bernardo Sayão, em Goiânia para uma exposição de motivos de a mesma cortar as férteis terras habitadas pela sua família e outros aventureiros. (Wikipedia, 2007) 


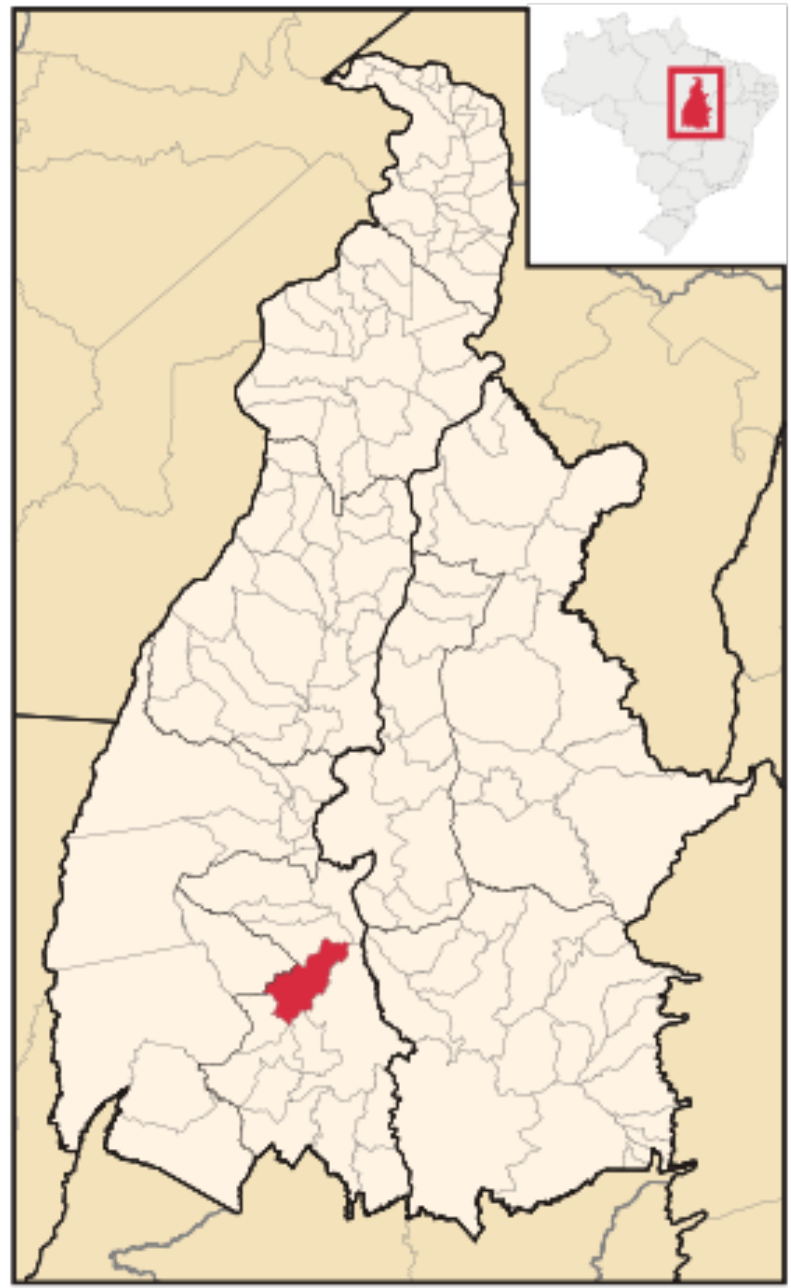

Figura 3. Mapa do estado do Tocantins, com destaque para o município de Gurupi. (Wikipedia, 2007)

A instalação definitiva do fundador de Gurupi na região se deu em 1952, ocasião em que concluiu a picada da rodovia projetada por Bernardo Sayão, até a estrada que ligava o município de Peixe a Porangatu; fez todo o levantamento da planta do município e construiu o primeiro comércio de Gurupi. 


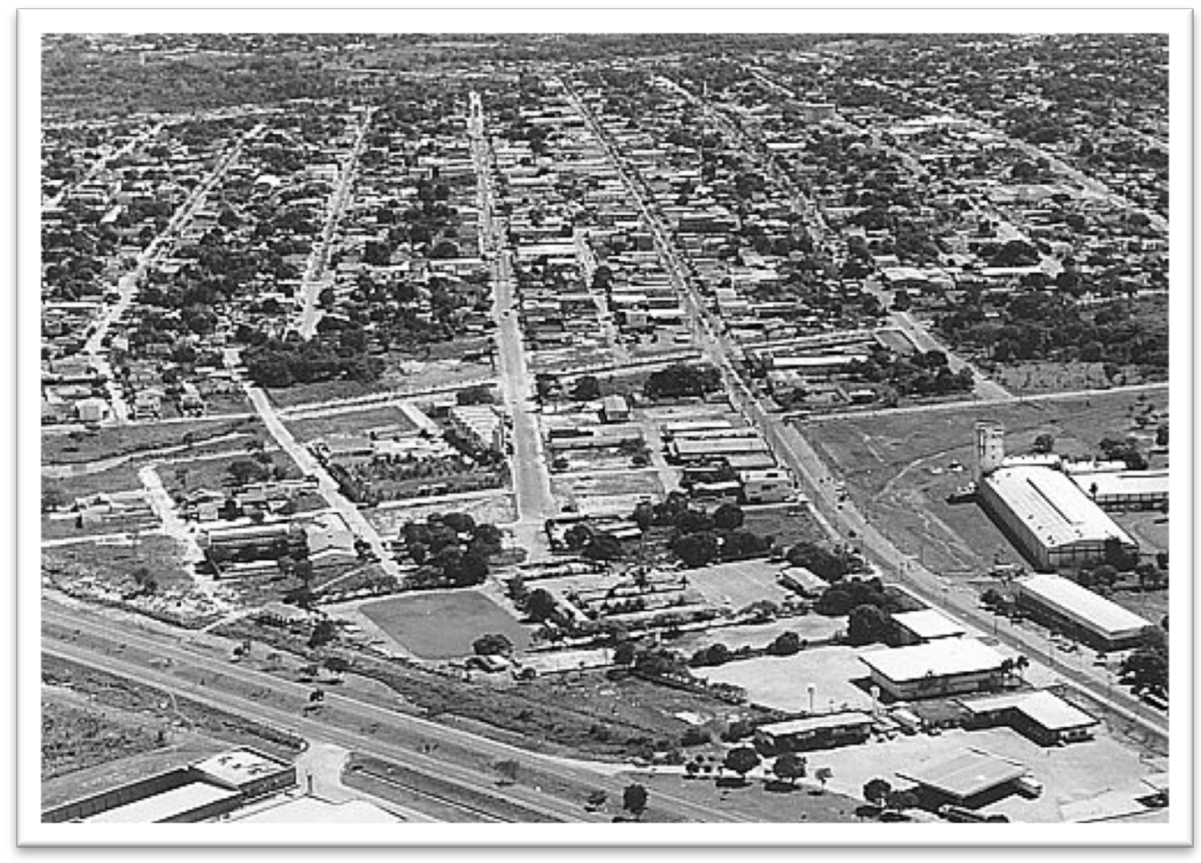

Figura 4. Foto aérea da cidade de Gurupi, Tocantins. (arquivo pessoal)

A partir daí, a paisagem do agreste foi dando lugar aos barracos de taipa dos novos moradores de várias outras localidades. A notícia do primeiro caminhão ao local já denominado de Gurupi é de setembro do mesmo ano, de propriedade do senhor Buta, que veio abastecer o comércio de Benjamim Rodrigues. A vocação para o comércio começou a partir desta data, e em pouco tempo a notícia se espalhou pelas regiões mais distantes e, com isso, atraiu interesses de moradores de outras localidades, como Porto Nacional, Peixe, Cristalândia, Dueré e Formoso do Araguaia. (Wikipedia, 2007)

O Tocantins historicamente apresentou uma população indígena significativa, que ainda tem um número significativo de representantes habitando principalmente as reservas indígenas. Ainda temos como povos formadores da população os mamelucos e cablocos principalmente oriundos do interior do nordeste. Na década de 
oitenta foi criado em uma região próxima um projeto agrícola de grande porte atraindo assim indivíduos de outras regiões do país, principalmente do sul. Assim temos uma grande diversidade de povos na cidade, a qual representa de fato um espelho da miscigenação do povo brasileiro.

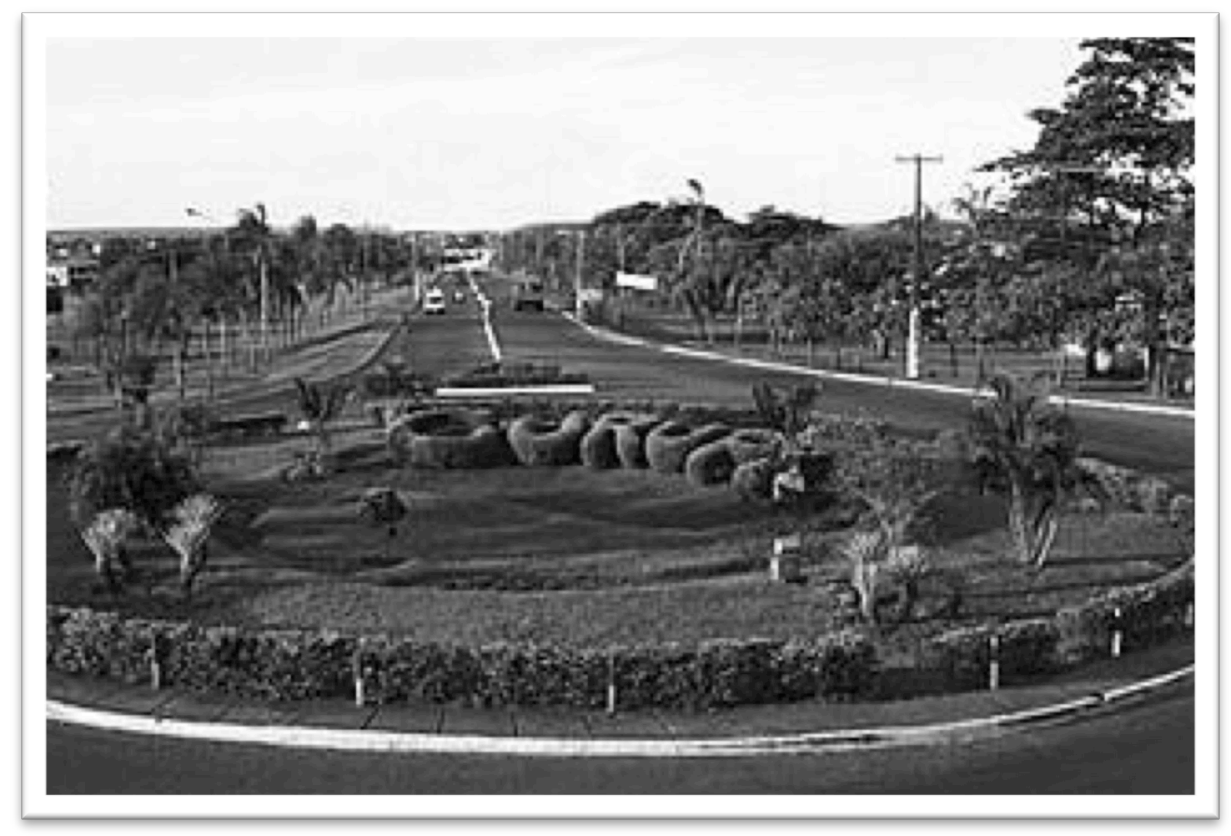

Figura 5. Foto da entrada principal da cidade de Gurupi - TO (arquivo pessoal).

\section{Justificativa}

Tendo em vista a escassez de dados de vícios de refração com base populacional no Brasil, primordialmente a miopia em adolescentes, justifica-se o presente estudo pela análise da freqüência de miopia como causa de baixa visão em uma localidade central do Brasil, com quadro demográfico característico da miscigenação nacional. 
Objetivos 
1. Determinar a freqüência de miopia como causa de baixa visão em sujeitos com idade variando de 10 a 15 anos, residentes na cidade de Gurupi.

2. Verificar possíveis fatores relacionados com a presença de miopia nesta faixa etária. 
Sujeitos e Métodos 


\section{Aspectos Éticos}

Este estudo foi aprovado pelo Comitê de Ética em Pesquisa da Universidade de São Paulo (processo número 1513/2007) (anexo 1). A recusa na participação e concessão do termo de consentimento livre e esclarecido pelos responsáveis foi considerada como o único critério de exclusão (anexo 2 e 4).

\section{População}

Gurupi é uma cidade do estado Tocantins, na Região Norte do Brasil. Localizase a uma latitude $11^{\circ} 43^{\prime} 45^{\prime \prime}$ sul e a uma longitude $49 \circ 04^{\prime} 07^{\prime \prime}$ oeste, estando a uma altitude de 287 metros. É a principal cidade do sul Tocantins, estando a $245 \mathrm{~km}$ de Palmas, capital do estado, e a 742 km de Brasília. Fica no limite divisório de águas entre o Rio Araguaia e o Rio Tocantins, às margens da BR-153, no quilômetro 663 no sentido Brasília à Belém. As principais atividades econômicas são a pecuária e a agricultura. É uma região com uma população essencialmente de baixa renda sendo o PIB per capita de 4.816 reais, enquanto um município de referência em termos de renda per capita (Ribeirão Preto - SP) era de 10.228 para o mesmo período, pelo que foi avaliado pelo IBGE.

Em função da baixa renda da população, grande parte da população é dependente dos serviços públicos de saúde. Porém, no que tange a oftalmologia, existe de forma regular apenas o serviço de urgência/emergência que é oferecido pelo Estado. A prefeitura municipal disponibiliza, de forma não muito clara, consultas oftalmológicas ambulatoriais por meio do serviço de assistência social para as pessoas mais carentes. 
Segundo o Instituto Brasileiro de Geografia e Estatística (IBGE), a população estimada no censo de 2007 era de 71.413 habitantes. Pelas estimativas do IBGE, em 2006 existiam 8.454 sujeitos na faixa etária de 10 a 15 anos representando 11,46\% da população.

\section{Desenho do Estudo e Seleção dos Pacientes}

Estudo transversal com base populacional, no qual foram avaliados sujeitos com idades variando entre 10 a 15 anos, de ambos os sexos. A faixa etária escolhida foi considerada como o único critério de inclusão.

O protocolo RESC define um padrão para pesquisa de dados de campo como descrito a seguir. É feita uma amostragem por conglomerados, baseados na distribuição de sexo e idade da população alvo (sujeitos de 10 a 15 anos de idade), prevalência prévia de erros refrativos do país ou de outros países com características sócio-demograficas semelhantes para a determinação do tamanho da amostra. Em função do uso de conglomerados, é feita um ajuste do tamanho da amostra estimada, o que faz com que este aumente geralmente 1,5 a 2 vezes. Há uma equipe de mapeadores que determina a área geográfica com exatidão de cada conglomerado e de responsáveis por enumerar, que visita cada domicílio e lista todos os seus residentes, obedecendo ao critério de ser considerado residente apenas quem reside há mais de seis meses neste local. Então, todos os sujeitos com idade entre 10 a 15 anos são convidados a participar do exame clínico oftalmológico em um local previamente determinado. 
O exame oftalmológico consta de acuidade visual sem correção, avaliação da motilidade e alinhamento ocular, retinoscopia e auto-refração após cicloplegia, exame externo, exame das estruturas da câmara anterior e do pólo posterior. (Negrel, Maul et al., 2000; Salomao, 2008)

Após a realização do RESC, o REWG concluiu que alguns países com população acima de 100 milhões de pessoas deveriam ser priorizados, dentre eles o Brasil. Foram sugeridas algumas alterações para facilitar a execução do protocolo, sem comprometimento dos resultados encontrados. Dentre estas, a redução do número de indivíduos a ser estudados minimizando assim as limitações na execução e custos. A faixa de idade deveria ser reduzida da anteriormente usada que era de 5 a 15 anos, para 11 a 15 anos uma vez que esta compreende os sujeitos com maior necessidade de identificação de erros refrativos. Para dinamizar a execução destes protocolos, passariam por exame oftalmológico somente dos indivíduos em que fosse encontrada alteração visual. Assim seriam reduzidos os exames em sujeitos normais. Também deveria ser levada em conta a possibilidade de se usar as escolas como base populacional em países com baixos índices de evasão escolar. (Group, 2002)Seguindo as modificações sugeridas, foram treinadas três pessoas que freqüentavam cursos superiores na área de saúde para realizarem a triagem em campo.

Para fins de execução do presente estudo, foi estimada a prevalência de miopia em $5 \%$, com um erro padrão estimado de $20 \%$ e um intervalo de confiança de $95 \%$, sendo calculado um número de 1.590 sujeitos para esta amostra.

Para a definição dos conglomerados a serem avaliados, foram utilizados os que foram anteriormente definidos pelo IBGE para a realização do Censo Demográfico 
Brasileiro de 2.000, uma vez que estes apresentavam uma distribuição equivalente entre si. Foi feita a opção de se selecionar por sorteio 50 conglomerados dos 59 que o IBGE utilizou para dividir toda a cidade de Gurupi, em função dos grupamentos para a realização do projeto piloto. Levando em conta os dados disponibilizados pelo escritório local do IBGE e o número de indivíduos previamente calculados para definir a amostra, obteve-se 32 sujeitos por conglomerado. Os esquemas dos conglomerados do IBGE apresentam uma seqüência dos quarteirões em ordem numérica e, cada quarteirão tem uma ordem numérica dos lotes que o compõe. Assim, durante a coleta de dados, os examinadores seguiram esta ordem, visitando casa a casa buscando completar os 32 sujeitos que se enquadravam nos critérios de inclusão. Nas residências onde os sujeitos não estavam presentes, foi agendada uma segunda visita em um horário mais propício. Já nas casas onde não havia ninguém no momento da visita, foi feita uma segunda visita em outra oportunidade. Não sendo encontrada nenhuma pessoa na segunda visita, esta casa foi descartada.

Foi treinado um grupo de seis examinadores com explanações teóricas e práticas sobre a metodologia que seria utilizada durante a execução da coleta de dados. Foi realizado um trabalho piloto com a participação de toda a equipe para testar a metodologia, avaliar e sanear as dificuldades encontradas. Durante a execução do projeto piloto, dois examinadores distintos, em tempos diferentes examinaram os mesmos sujeitos e os seus resultados foram comparados buscando diferenças. As poucas encontradas foram sanadas revendo os conceitos utilizados. 


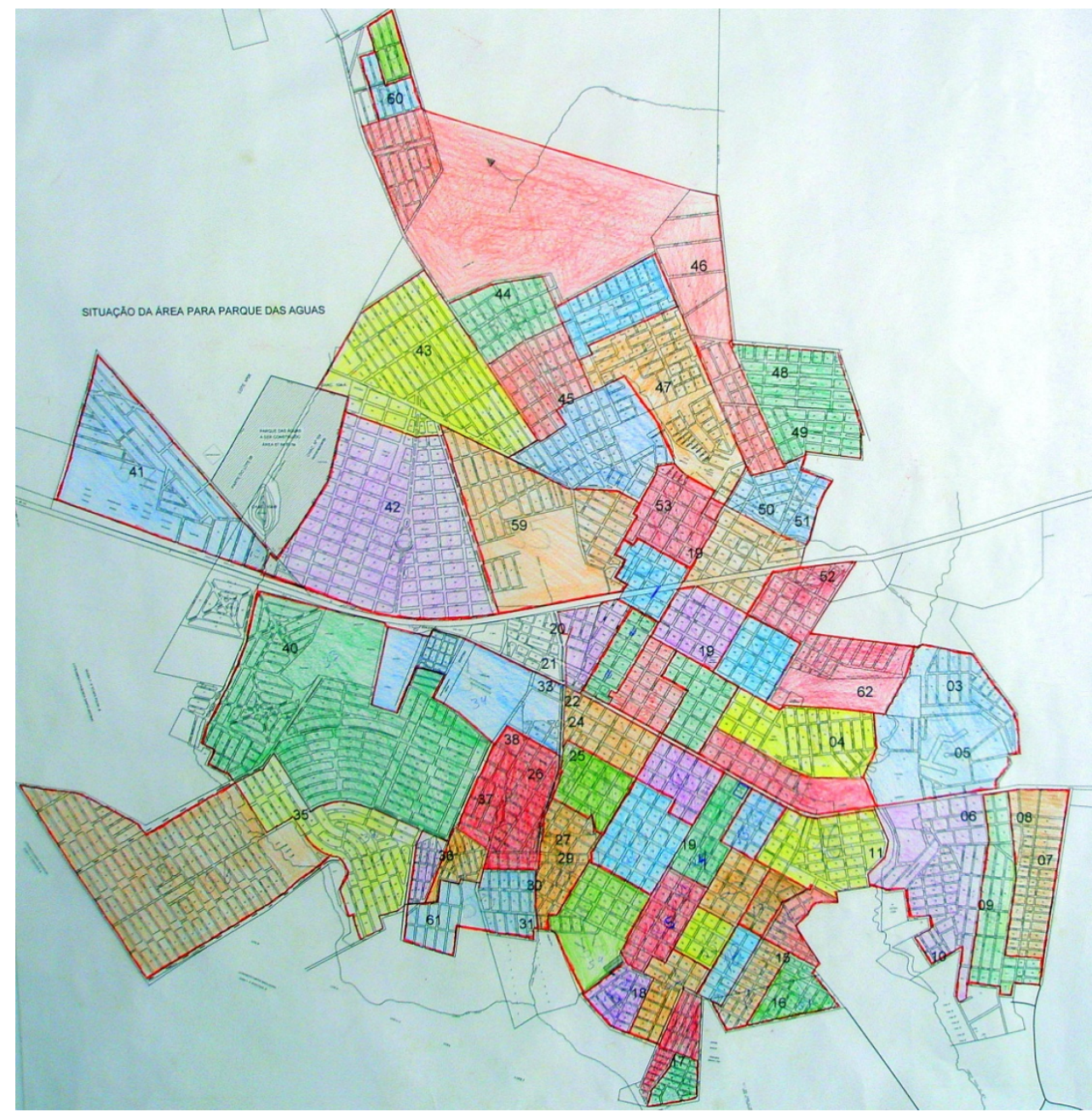

Figura 6. Mapa da cidade de Gurupi, com a divisão dos grupos utilizados para a realização do trabalho de campo.

Os exames foram realizados entre junho e agosto de 2007. As crianças foram avaliadas nos locais onde residiam, e posteriormente encaminhadas para exame em consultório quando apresentavam redução da acuidade visual, conforme detalhado abaixo.

\section{Coleta de Dados}


Conforme definido, os sujeitos examinados deveriam apresentar idade variando de 10 a 15 anos completos. Após identificar uma residência onde existia ao menos uma criança que se enquadrava nos critérios de inclusão, um responsável maior de dezoito anos era identificado e informado sobre a pesquisa, e recebia um Termo de Esclarecimento Consentido de Pesquisa (anexo 1). Uma vez, com o consentimento do responsável, este fornecia os dados para o preenchimento de um questionário (anexo 2) que constava o nome, data de nascimento, sexo, endereço, se freqüentava a escola, se já havia consultado algum oftalmologista, se utilizava óculos, há quanto tempo estava com aqueles óculos e com que freqüência os utilizava.

Em seguida, o examinador media com um cordame uma distância de quatro metros do examinado e solicitava para que fosse ocluído o olho direito com um copo descartável opaco (de café), sempre sem uso de nenhuma correção. Era então mostrada pelo examinador uma linha de cinco optotipos em E da Tabela LogMar equivalente a 20/32. Após a leitura da linha, a mesma era apresentada em outra posição e testada a acuidade visual do outro olho. Os que não visualizassem de forma correta 5 optotipos com qualquer um dos olhos eram encaminhados para o exame no consultório oftalmológico.

Ao chegarem para o exame em consultório oftalmológico, após a informação aos responsáveis do procedimento que seria realizado e o consentimento dos mesmos (anexo 3), era preenchida uma nova ficha (anexo 4) onde constava o nome, número do exame de campo, idade, se utilizava óculos. Os sujeitos do sexo feminino eram inquiridos sobre a menarca. O oftalmologista realizava o teste de cobertura (Cover Test) para avaliar o alinhamento ocular. Após isso, era realizada a cicloplegia com uma 
gota de ciclopentolato $1 \%$ em cada olho e uma segunda gota após dez minutos de intervalo. (Negrel, Maul et al., 2000; Fotedar, Rochtchina et al., 2007) Após 30 minutos da segunda gota, as pupilas eram avaliadas. As que apresentaram diâmetro maior que $6 \mathrm{~mm}$ e/ou não apresentaram reflexo pupilar, foram consideradas dilatadas. Os que não se enquadraram nestes critérios, receberam uma terceira gota. Dos sujeitos que compareceram ao exame, não houve nenhuma recusa do uso do ciclopentolato e todos se submeteram ao exame.

Quando constatada a cicloplegia, era realizada a refratometria computadorizada com refrator automático Topcon (KR 8800, Japão). Em seguida, era realizada a refração subjetiva utilizando uma tabela logMAR retro-iluminada. Os que melhoram a acuidade visual e necessitavam de óculos, receberam a prescrição dos óculos e uma armação doada por colaboradores. Para tanto, os pesquisadores conseguiram um acordo com uma rede de ópticas local que se propôs a fornecer as lentes. Os pacientes que não apresentaram visão melhor que $20 / 20$ no pior olho foram investigados no intuito de se diagnosticar a causa da limitação visual com biomicroscopia e fundoscopia indireta. Seguido o padrão proposto pelo RESC foram adotados, além dos erros refrativos, os diagnósticos de tracoma, opacidade de córnea, catarata congênita, alterações da retina, ambliopia e outras. (Negrel, Maul et al., 2000). Para o diagnostico e classificação do tracoma, foram utilizados os critérios da OMS. As alterações retinianas foram apenas avaliadas do ponto de vista funcional, ou seja, se eram as responsáveis prováveis pela deficiência visualpor si só. Com relação a ambliopia, foram considerados amblíopes sujeitos que apresentavam como provável causa de baixa visualanisiometropia significativa, restrição do estímulo visual por causas diversas ou estrabismo. (Yanoff, 2004) 
Foram considerados míopes os pacientes que necessitaram de correção a partir de 0,5 dioptrias negativas e hipermétropes aqueles que necessitaram de duas ou mais dioptrias positivas. Os astigmatismos foram classificados em $<-0,50,-0,50$ até $-2,00$ e $>$ $-2,00$ dioptrias cilíndricas.

\section{Análise Estatística}

Os dados obtidos foram analisados estatisticamente e foram estabelecidas relações. Utilizaram-se ferramentas de estatística descritiva tomando-se média com desvio padrão ( \pm SD) e para as proporções, porcentagem e intervalo de confiança $95 \%$ (IC 95\%). Comparações de variáveis categóricas foram feitas por teste exato de Fisher e de dados contínuos por teste $t$ de Student. Sendo tomados sensibilidade, especificidade, odds ratio e intervalos de confiança. Estas análises foram feitas empregando o software Prism version 4 (GraphPad, Inc., USA).

Para a análise de regressão multivariada, aplicou os comandos: PROC FREQ para cálculo das freqüências das variáveis e o comando PROC LOGIST para o cálculo dos Odds ratio: bruto e ajustado, empregando o software SAS 9 (SAS Institute Inc., USA). Significância estatística foi atribuída com $P<0.05$. 
Resultados 


\section{Dados gerais}

Os dados expostos a seguir foram coletados durante a fase de campo da pesquisa. Foram examinadas 1590 crianças sendo, 814 do sexo masculino e 776 do sexo feminino correspondendo a $51 \%$ e $49 \%$ da amostra respectivamente. As idades variaram entre 10 a 15 anos completos na data do exame, sendo que 246 estavam com 10 anos, 311 com 11 anos, 340 com 12, 298 com 13, 220 com 14 e 175 com 15 anos conforme a figura 5 . A média de idade de ambos os sexos foi de $12,4 \pm 1,6$ anos para o sexo masculino e $12,2 \pm 1,6$ anos para o sexo feminino. Com relação à freqüência escolar, apenas três $(0,2 \%)$ sujeitos responderam não estar freqüentando a escola.

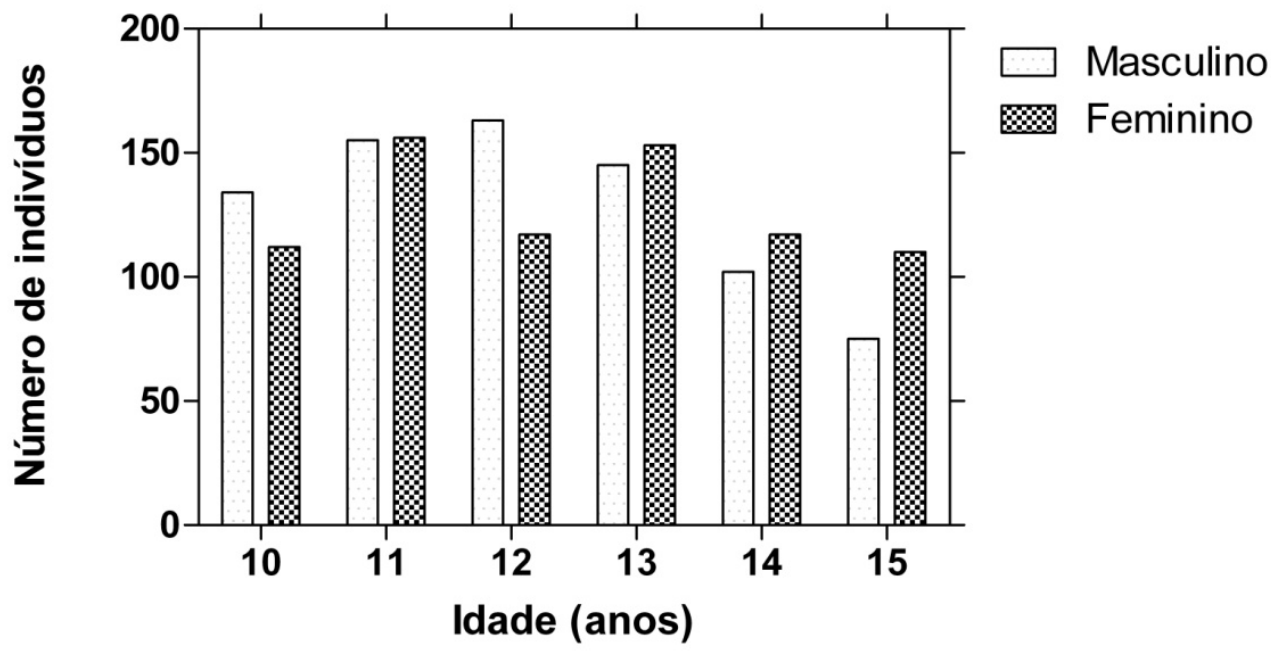

Figura 7. Distribuição dos indivíduos investigados divididos por sexo segundo cada faixa etária.

Foi questionado se a criança já havia anteriormente consultado um médico oftalmologista. Responderam negativamente 1152 (72\%) e positivamente 438 (28\%). 
Quanto ao uso de correção óptica, responderam positivamente 108 (6,8\%), sendo 42 (39\%) do sexo masculino e $65(61 \%)$ do sexo feminino. O tempo de uso variou de 1 a 120 meses com uma média de $28,6 \pm 23,7$ para o sexo masculino e $27,5 \pm$ 24,5 meses para o feminino.

\section{Dados da avaliação oftalmológica}

Após o exame de campo, 167 sujeitos não enxergaram, com pelo menos um dos dois olhos, os optotipos mostrados. Foram submetidos ao exame oftalmológico no consultório 127 (76\%) sujeitos, havendo 40 faltosos (24\%), mesmo após três convocações por telefone. Os que não possuíam telefone foram visitados uma segunda vez, sendo que no caso dos mais carentes foi disponibilizada uma forma de transporte gratuita até o local de exame.

Dos encaminhados ao consultório, após a refração subjetiva sob cicloplegia, 61 sujeitos (48\%) não apresentaram necessidade de uso de lentes corretoras. Foram prescritas lentes corretoras para sujeitos que apresentaram melhora da acuidade visual com graus maiores que 1,5 dioptrias esféricas positivas e menores que 0,5 dioptrias esféricas negativas. Em grandes anisiometropias, quando apenas um olho apresentava grau significativo e sem melhora importante com a correção, não houve prescrição. Receberam prescrição 65 (52\%) sujeitos, sendo que 15 foram corrigidos com lentes que apresentaram equivalente esférico positivo, variando de 0,25 até 7,00 dioptrias esféricas. 


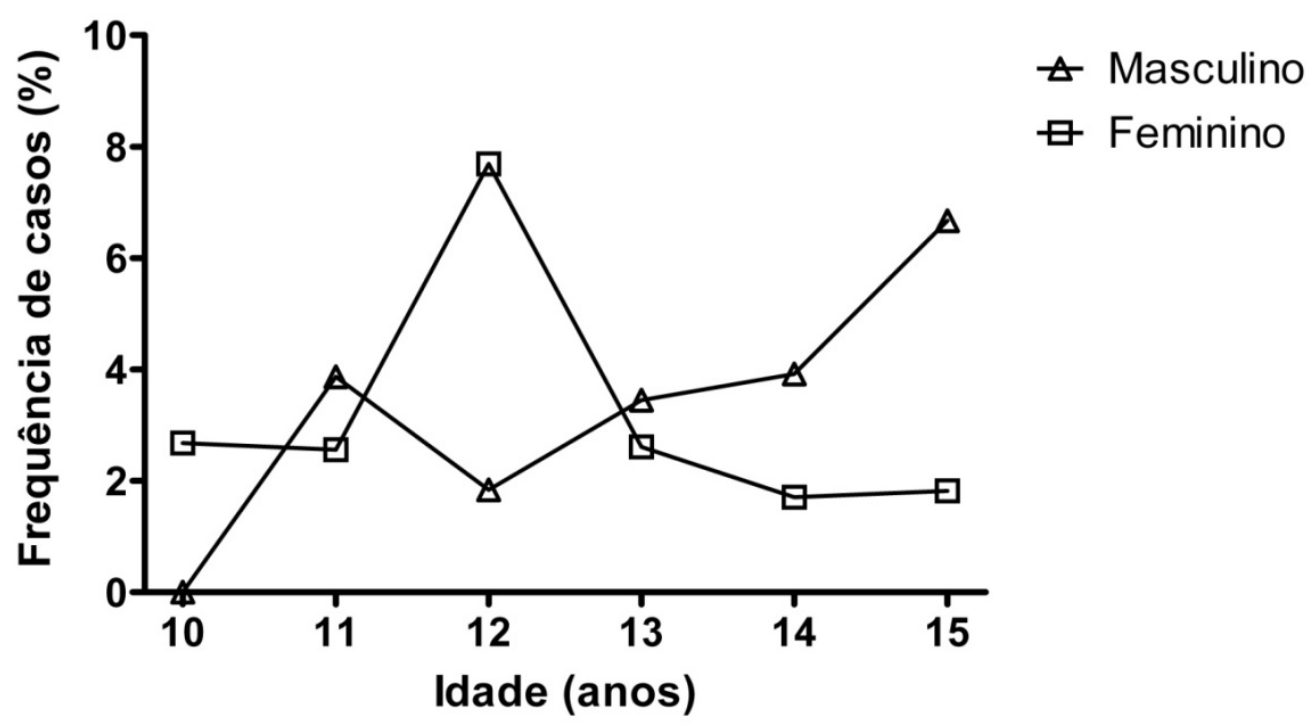

Figura 8. Freqüência de miopia em sujeitos do sexo masculino e feminino pela idade. Foram considerados míopes os que apresentaram equivalente esférico menor que -0,50 em pelo menos um dos olhos.

Houve prescrição de lentes com equivalente esférico negativo maior que 0,5 dioptrias em 50 sujeitos (39,37\%; IC 95\%: 30,78\% - 48,43\%) com variação de -0,50 até 9,00 dioptrias esféricas, sendo $23(45 \%)$ do sexo masculino e 28 (55\%) do sexo feminino. Assim foi encontrada a freqüência de 3,14\% (IC 95\%: 2,43\% - 4,13\%) de miopia na amostra estudada, sem diferença estatística $(p=0,578)$ de gênero, sendo 3,07\% masculinos e 3,61\% femininos.

Com relação aos equivalentes esféricos por sexo, foi encontrada para os sujeitos masculinos média de $-0,96 \pm 1,89$ e $-0,77 \pm 2,62$ para os femininos $(p=0,537)$. 


\section{Masculino}

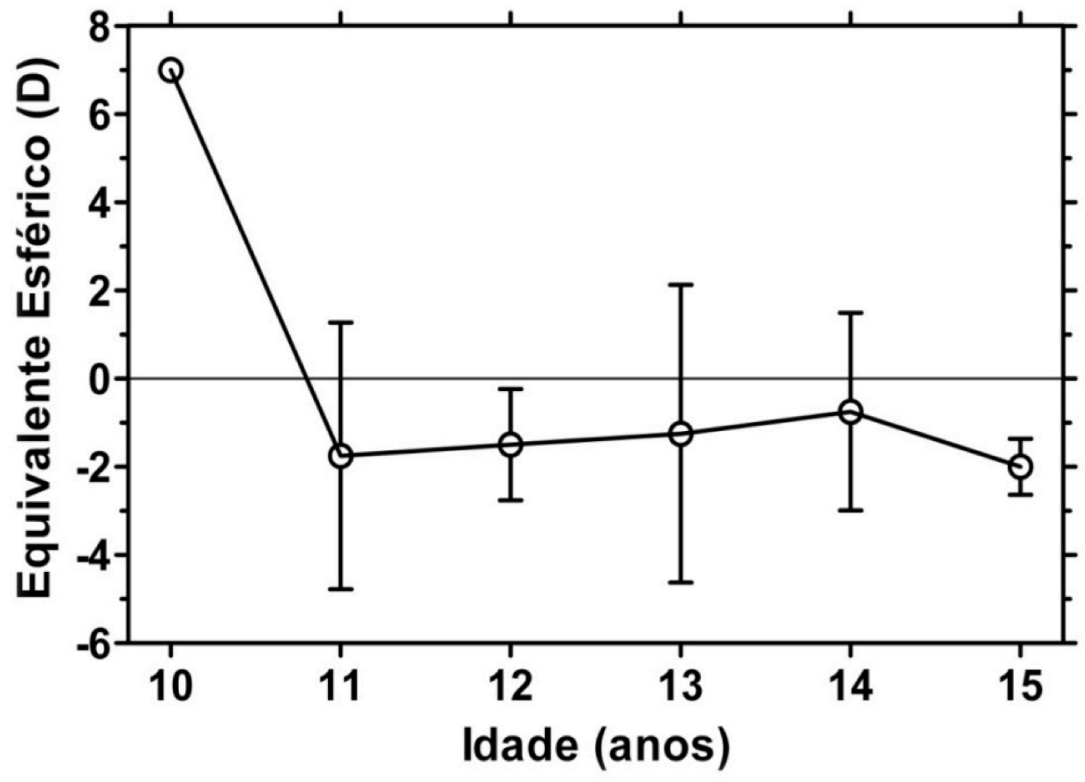

Feminino

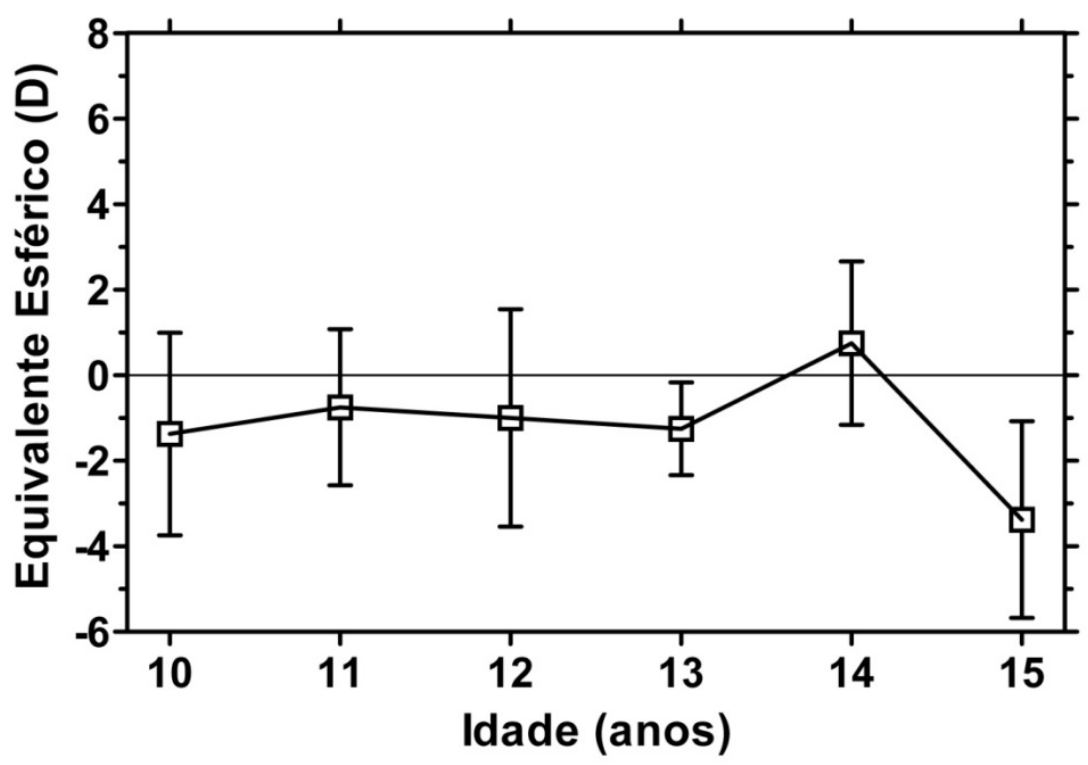

Figura 9. Média dos equivalentes esféricos do olho direito pela idade por sexo e idade dos sujeitos examinados no consultório (Acima: sexo masculino; abaixo: sexo feminino). Os desvios padrão são representados pelas barras verticais. 


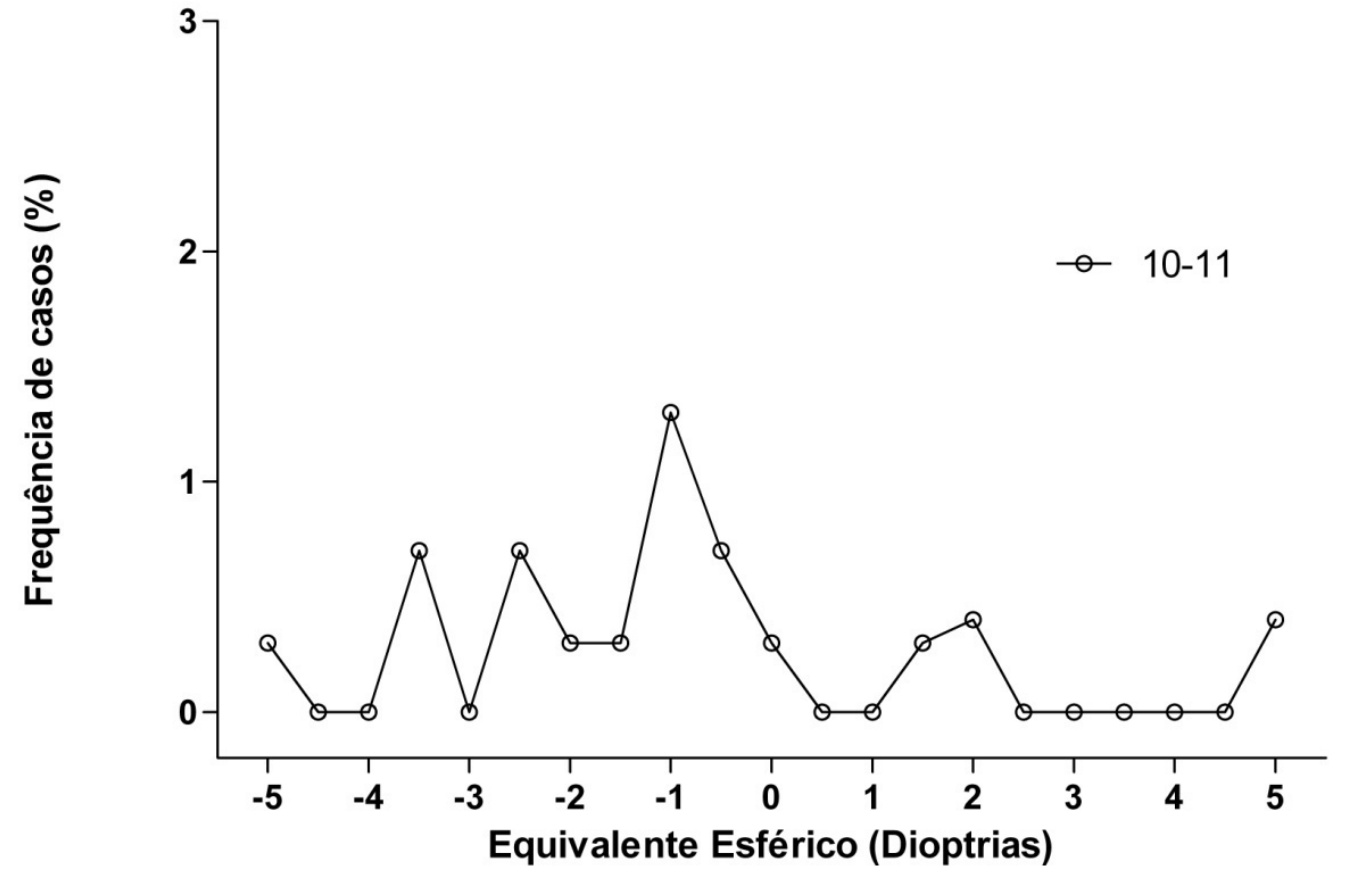

Figura 10. Distribuição do equivalente esférico dos erros refrativos dos olhos direitos dos sujeitos com idade de 10 a 11 anos. Os pontos representam um intervalo de meia dioptria (por exemplo, aqueles com 1 dioptria compreendem os sujeitos com equivalente variando entre 0,75 e 1,25 dioptrias). Os pontos das extremidades representam os sujeitos com $\mathrm{EE}<$ ou igual a $-5,00$ e $>$ ou igual a 5,00.

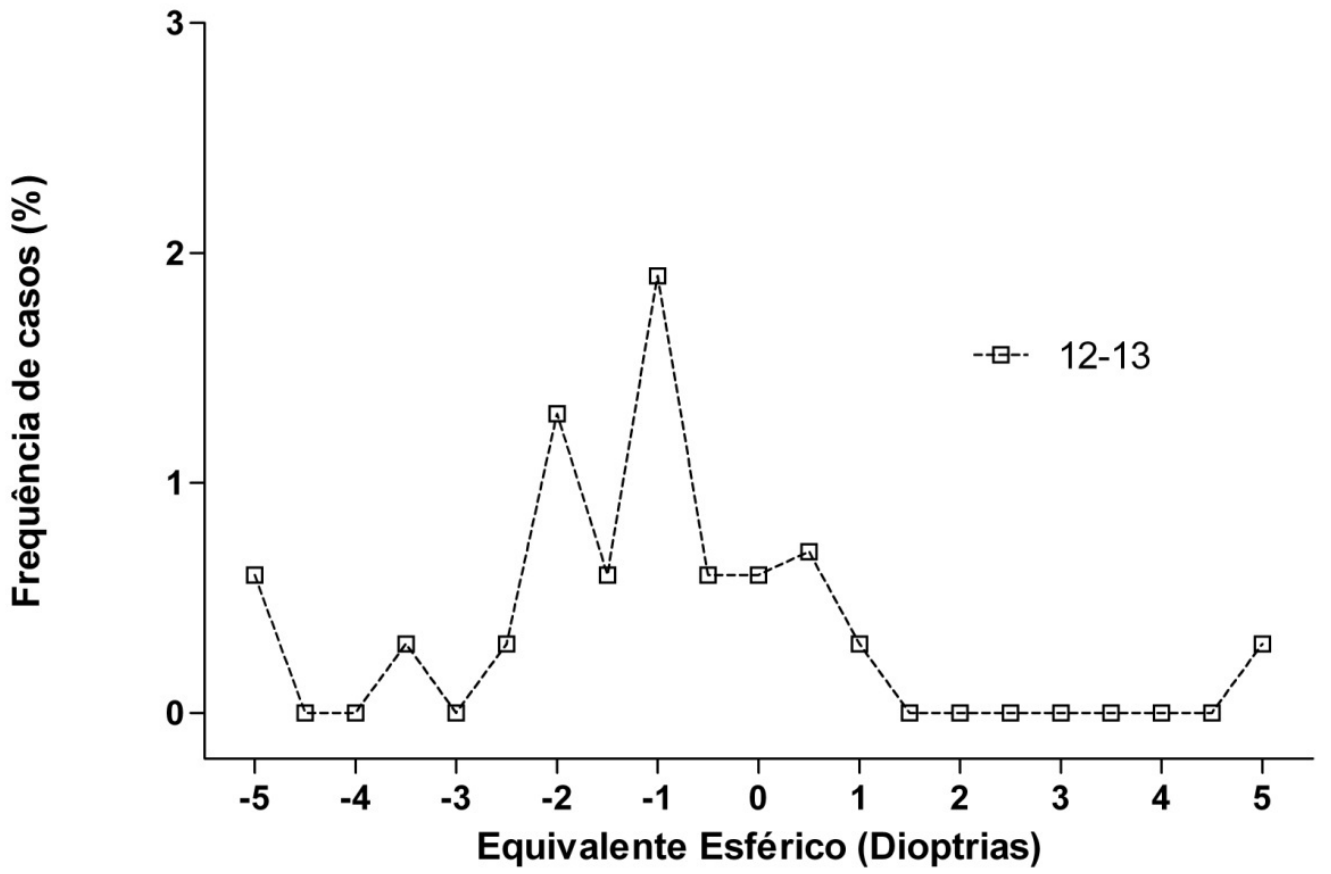

Figura 11. Distribuição do equivalente esférico dos erros refrativos dos olhos direitos dos sujeitos com idade 12 a 13 anos. Os pontos representam um intervalo de meia dioptria (por exemplo, aqueles com 
1 dioptria compreendem os sujeitos com equivalente variando entre 0,75 e 1,25 dioptrias). Os pontos das extremidades representam os sujeitos com $\mathrm{EE}<$ ou igual a $-5,00$ e $>$ ou igual a 5,00.

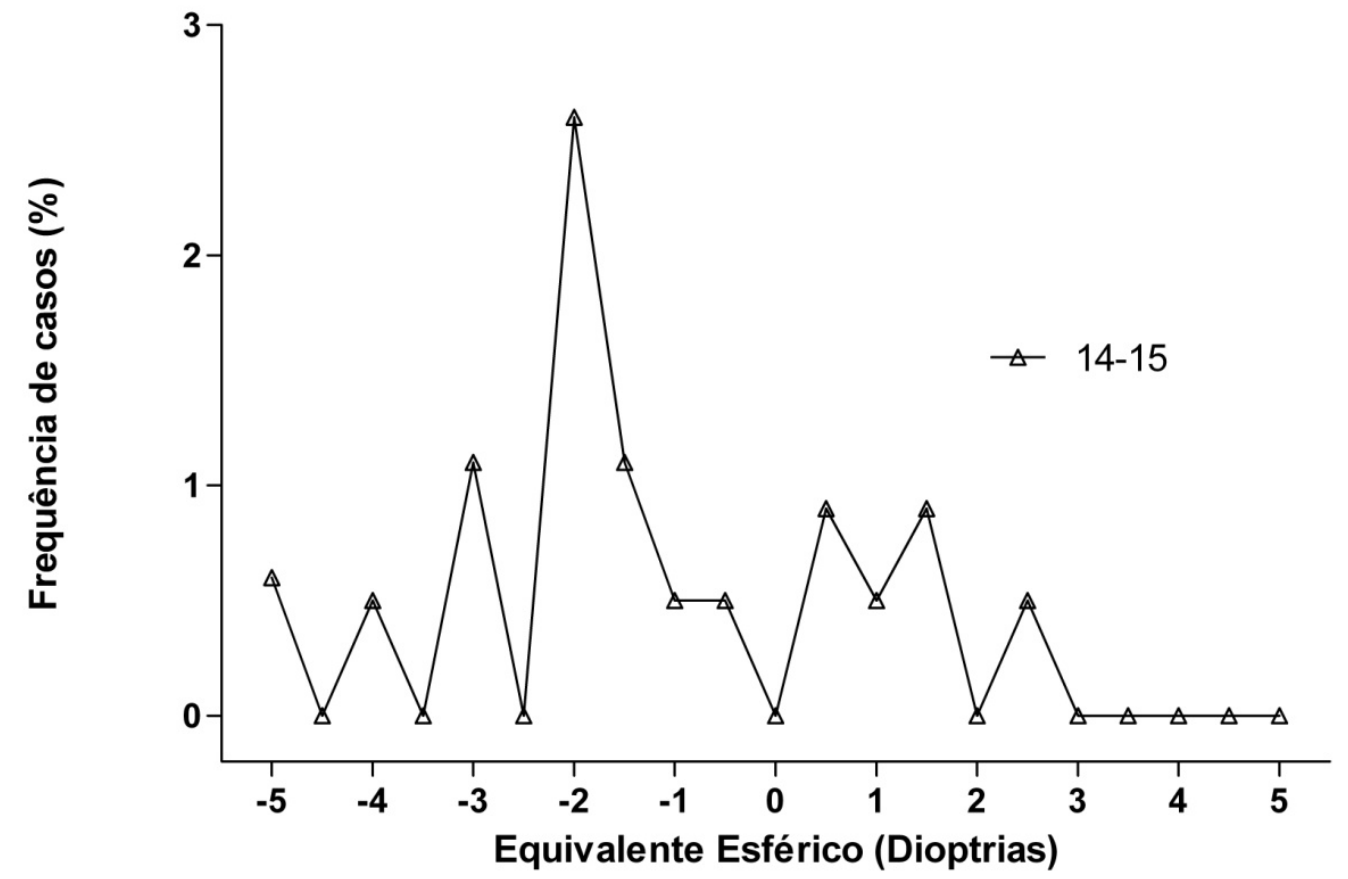

Figura 12. Distribuição do equivalente esférico dos erros refrativos dos olhos direitos dos sujeitos com idade de 14 a 15 anos. Os pontos representam um intervalo de meia dioptria (por exemplo, aqueles com 1 dioptria compreendem os sujeitos com equivalente variando entre 0,75 e 1,25 dioptrias). Os pontos das extremidades representam os sujeitos com $\mathrm{EE}<$ ou igual a $-5,00$ e $>$ ou igual a 5,00.

Para fins de análise multivariada da miopia, foram estudados os fatores:

1. Sexo;

2. Idade, dividida nas faixas etárias: 10-11 anos, 12-13 anos e 14-15 anos;

3. Uso prévio de correção óptica;

4. Região de estudo, considerando região 1: regiões centrais, composta por pessoas de melhor poder aquisitivo, e região 2: regiões da periferia, composta por pessoas de baixo poder aquisitivo;

5. Presença de consulta prévia a um oftalmologista. 
Com relação aos diversos fatores estudados, não se observou significância estatística nas associações (tabela 3). Além disso, não se observou diferença significante na análise da variável "presença de menarca" para os sujeitos do sexo feminino (OR = 5,1; IC 95\%=0,54 - 48,9).

Tabela 3. Freqüência das variáveis em estudos, com o odds ratio bruto e ajustado, considerando a variável miopia. Todas as comparações não alcançaram significância estatística $(p>0,05)$.

\begin{tabular}{|c|c|c|c|c|c|}
\hline & \multicolumn{2}{|c|}{ Miopia } & \multirow[b]{2}{*}{ Total } & \multirow{2}{*}{$\begin{array}{l}\text { OR Bruto } \\
\text { (IC 95\%) }\end{array}$} & \multirow{2}{*}{$\begin{array}{l}\text { OR Ajustado } \\
\qquad \text { (IC 95\%) }\end{array}$} \\
\hline & Não & Sim & & & \\
\hline \multicolumn{6}{|l|}{ Sexo } \\
\hline *Feminino & $7(21 \%)$ & 26 (79\%) & 33 & \multirow[b]{2}{*}{$0,8(0,2 ; 2,5)$} & \multirow[b]{2}{*}{$0,7(0,2 ; 2,7)$} \\
\hline Masculino & $8(25 \%)$ & $24(75 \%)$ & 32 & & \\
\hline \multicolumn{6}{|l|}{ OCC } \\
\hline Não & $10(32 \%)$ & 21 (68\%) & 31 & \multirow[b]{2}{*}{$0,4(0,1 ; 1,2)$} & \multirow[b]{2}{*}{$0,3(0,1 ; 1,3)$} \\
\hline *Sim & $5(15 \%)$ & $29(85 \%)$ & 34 & & \\
\hline
\end{tabular}

\section{Consulta prévia}

$\begin{array}{llllll}\text { Não } & 4(27 \%) & 11(73 \%) & 15 & 0,8(0,2 ; 2,9) & 1,2(0,2 ; 5,7) \\ \text { *Sim } & 22(22 \%) & 39(78 \%) & 50 & \end{array}$

\section{Regiões}

$\begin{array}{llllll}* 1 & 12(21 \%) & 45(79 \%) & 57 & 0,4(0,1 ; 2,1) & 0,5(0,1 ; 3,1) \\ 2 & 3(37 \%) & 5(63 \%) & 8 & \end{array}$

\section{Idade (anos)}

$\begin{array}{lllll}* 10 \text { e } 11 & 4(22 \%) & 14(78 \%) & 18 & \\ 12 \text { e } 13 & 5(18 \%) & 23(82 \%) & 28 & 1,3(0,3 ; 5,7) \quad 1,3(0,3 ; 5,9)\end{array}$


14 e $15 \quad 6(32 \%) \quad 13(68 \%) \quad 19 \quad 0,6(0,2 ; 2,7) \quad 0,7(0,1 ; 3,3)$

Total $\quad 15 \quad 50$

* variável de referência. OCC - uso prévio de óculos.

Dentre as causas de baixa de visão, os erros refrativos foram responsáveis por $48(72 \%)$, tendo como causas isoladas, 46 sujeitos com miopia, dois com hipermetropia e um com catarata. Foram observados oito sujeitos (12\%) que apresentavam baixa acuidade visual por causas combinadas, sendo seis com erro refrativo e ambliopia e dois com associação entre erro refrativo e alteração retiniana.

Tabela 4. Causas de deficiência de visão.

\begin{tabular}{llc}
\hline Causa & Número de sujeitos (\%) & IC 95\% (\%) \\
\hline Erros refrativos & $48(37,80)$ & $29,39-46,79$ \\
\hline Ambliopia + refração & $6(4,72)$ & $1,75-9,99$ \\
\hline Alterações retinianas + refração & $2(1,57)$ & $0,19-5,57$ \\
\hline Catarata congenital & $1(0,79)$ & $0,02-4,31$ \\
\hline Falsos positivos & $70(55,12)$ & $45,98-63,98$ \\
\hline
\end{tabular}


Discussão 
O protocolo RESC foi elaborado com o intuito de se avaliar grandes populações com um padrão único de metodologia, assim possibilitando a comparação entre os valores encontrados. Após sua realização em vários países com Nepal, Chile, China, Índia, África do Sul, Malásia e Brasil (Maul, Barroso et al., 2000; Negrel, Maul et al., 2000; Pokharel, Negrel et al., 2000; Zhao, Pan et al., 2000; Salomao, 2008), o REWG fez a sugestão de se simplificar visando facilitar a realização de futuros estudos, sem acarretar comprometimento da qualidade do resultado alcançado. (Group, 2002) Este trabalho foi a primeira experiência de aplicação no país do protocolo RESC modificado na população de uma cidade.

Os trabalhos anteriores relativos a erros refrativos realizados em nosso país geralmente se utilizaram da população escolar dos locais examinados (Kara-Jose, 1982; Firmo, 1997; Schimiti, 2001), não podendo ser classificados como estudos epidemiológicos de base populacional. Se forem consideradas as informações cedidas pelos órgãos públicos, pode-se admitir a utilização da população escolar para estudos de levantamento de vícios de refração na cidade de Gurupi. Segundo a Delegacia Estadual de Educação a evasão escolar nesta cidade, na faixa de idade investigada, foi de $3,2 \%$ no ano de 2007. (Dre, 2007). Assim, a população escolar poderia ser utilizada de forma representativa para o presente estudo sem o comprometimento da qualidade deste. A proposta da realização deste projeto com base populacional foi de estudar uma cidade de pequeno porte para os padrões nacionais, valendo-se das alterações no protocolo RESC sugeridas pelo encontro do REWG. Dessa forma, poderse-ia levantar dados comparáveis dentro dos padrões sugeridos pela OMS. 
Alguns fatores facilitaram a execução em função de ser uma cidade interiorana. Com distâncias menores, não houve necessidade de se montar uma estrutura oftalmológica móvel, sendo possível encaminhar os sujeitos selecionados para uma única referência fixa, reduzindo os custos e dinamizando a execução. Entretanto, ainda assim houve uma perda, principalmente dos locais mais periféricos e carentes. São possíveis justificativas para este fato, a provável falta de condições ou tempo para se locomover até o local do exame e desinteresse dos próprios responsáveis, a despeito das informações sobre a importância do exame e sua gratuidade.

Não se pode afirmar que exista uma diferença tão significativa entre o zoneamento de ocupação pelos habitantes do ponto de vista do poder aquisitivo. Durante o desenho do estudo, foi argumentada com um dos responsáveis pelo escritório do IBGE local, a possibilidade de se dividir a cidade do ponto de vista sócioeconômico. Segundo a opinião deste, isso apresentaria uma grande quantidade de vieses, sendo possível apenas com segurança se definir as regiões extremamente pobres. Existe uma periferia muito pobre (denominada região 2), porém os bairros mais centrais (região 1) não apresentam um padrão sócio-econômico muito bem definido, dificultando assim comparações sobre esta variável. Em função disto, foi feita a tentativa de se utilizar apenas a comparação destas duas regiões, sempre tendo em mente a limitação disto. Após a regressão, não foi encontrada uma diferença significativa da quantidade de erros refrativos entre as duas regiões. Um dos fatores que pode ter limitado a comparação entre os grupos, foi o número limitado de sujeitos examinados. 
Outra limitação encontrada, no que tange à cidade, foi a impossibilidade de se caracterizar do ponto de vista étnico seus habitantes, uma vez que a grande maioria dos residentes é proveniente de diversas regiões do país (incluindo povos indígenas), havendo intensa miscigenação. Como foi exposto anteriormente, a cidade de Gurupi é relativamente nova, com aproximadamente 50 anos, tendo a sua história intimamente relacionada com a construção da rodovia BR-153. Sendo assim, os habitantes mais antigos da região seriam os indígenas. Entretanto, em função da relativa distância das tribos mais próximas, não existem tantos indígenas com residência fixa em Gurupi. No desenho do estudo foi aventada a possibilidade de se tentar investigar esta variável. Porém, após várias tentativas de se criar uma ferramenta que pudesse fornecer uma informação confiável, optou-se por não investigar este dado.

A realização deste estudo proporcionou uma oportunidade de se avaliar a possibilidade de execução do protocolo, já com as modificações sugeridas pelo REWG. (Group, 2002) Observou-se que com uma equipe pequena, bem treinada, sem grandes quantidades de recurso financeiro, que geralmente são necessários para a realização de um trabalho de campo, podem-se alcançar dados substanciais. Algumas adaptações foram realizadas para facilitar a execução do trabalho de campo. Por exemplo, para se ocluir o olho não examinado, foi utilizado um copo descartável de café (branco opaco). Para os exames oftalmológicos, disponibilizamos a possibilidade de agendamento de consulta, diminuindo assim as limitações de disponibilidade de horários apresentadas pelos responsáveis.

Este estudo avaliou uma parcela da população, que mesmo sendo representativa para a faixa etária avaliada, não nos permite extrapolar os dados 
encontrados em termos de prevalência de miopia, uma vez que não foi avaliada a população em sua totalidade. Os casos identificados foram aqueles rastreados pelo baixo nível na acuidade visual, o que representa uma parcela da população. Dentro desse raciocínio, poder-se-ia ter perdas de indivíduos com baixa miopia, que apresentaram acuidade visual considerada como normal. Da mesma forma, casos de hipermetropia e astigmatismo menos elevados podem não ter sido selecionados para o exame de consultório. Assim, os dados encontrados referem-se a prevalência de baixa acuidade visual $(A \bigvee<20 / 32)$ nesta população e a freqüência de miopia como causa.

Com relação à opção de se realizar o estudo somente sobre miopia e não de todos os erros refrativos da faixa de idade proposta, deve-se mencionar que o estudo teve como limitação a capacidade de execução. Isso foi devido ao tamanho da amostra calculada previamente, tendo em consideração a prevalência de todos os erros refrativos encontrada em estudos anteriores (ver trabalhos abordando RESC - tabela 1). Assim, como a prevalência era relativamente baixa, isso faria que o $\mathrm{N}$ elevado. Isso porque quanto mais raro é o evento investigado, maior será o $\mathrm{N}$ pesquisado necessário para se encontrar a alteração em questão. Este também foi o motivo da escolha da faixa etária estudada, 10 a 15 anos de idade. Mesmo alguns programas de apoio (como por exemplo, VISION 2020) incentivam trabalhos nesta parcela da população em função da maior prevalência de miopia.

Os valores encontrados da freqüência de miopia se mostraram semelhantes aos encontrados em outras avaliações anteriores no Brasil e América do Sul (ver tabela 2). Os trabalhos realizados anteriormente, na região Norte, mostraram também valores 
de miopia muito baixos para idades semelhantes às avaliadas neste estudo. Entretanto, divergem muito dos povos asiáticos que apresentam valores bem superiores (Tabela 1).

A despeito de estudos mostrando a progressão cada vez mais significativa da miopia nas populações asiáticas (Fan, Lam et al., 2004; Saw, Tong et al., 2005), foram aventadas algumas teorias, porém sem nenhuma explicação definitiva.(Loman, Quinn et al., 2002) No presente estudo, foi feita uma tentativa de se associar sexo e idade, além de outros fatores, tais como nível sócio-econômico, uso anterior de correção e miopia. No entanto, não foi encontrado nenhum fator com valor significativo de associação. Poderia ser indicada uma investigação especifica de maior porte e com maiores detalhes neste sentido, em função das limitações expostas no presente estudo.

Com relação ao astigmatismo (Anexo 4), os resultados encontrados se assemelham com os encontrados em estudos nacionais anteriores, a despeito do fato de que a presente análise teve como base pessoas com baixa visão. (Hatakeyama, 1985; Garcia, Orefice et al., 2005; Estaica, 2007)

Como a faixa etária avaliada não é muito extensa, não foram encontradas diferenças significativas entre as idades estudadas. Com relação ao sexo, não houve uma diferença significativa.

Com relação à distribuição das idades investigadas, o número reduzido de sujeitos com idades mais avançadas, principalmente 15 anos, merece destaque. Isso se deve em primeiro lugar ao fato que os sujeitos raramente eram encontrados em suas residências nos horários das visitas, mesmo após um novo agendamento. Uma das 
causas prováveis, talvez seja a maior autonomia e mobilidade destes. Outro fator que também contribuiu foi o de alguns, mesmo após a explanação sobre a pesquisa, se recusarem a participar por motivos diversos.

Os erros refrativos foram a principal causa de deficiência de visão, seguidos pela ambliopia e alterações retinianas (principalmente placas maculares). Não foi encontrada nenhuma criança com deficiência de visão secundária a tracoma (tabela 4).

A tentativa de se correlacionar outros fatores com a miopia ficou comprometida em função do tamanho da amostra ser inferior ao necessário para estas inferências. Assim, fica inviabilizada qualquer conclusão destas associações.

O presente estudo possibilitou a descrição da possibilidade de se levantar uma alta freqüência de miopia (quase $40 \%$ dos erros refrativos), na faixa etária da população que se apresenta com prevalência mais alta, com base populacional no Brasil. Acredita-se que, a partir de então, novos horizontes poderão ser traçados para averiguação de dados gerais de vícios de refração, em especial a miopia, em nível nacional. 
Conclusões 
1. A freqüência encontrada foi de $3,2 \%$ de miopia como causa de deficiência da visão em sujeitos com idade 10 a 15 anos na cidade de Gurupi - TO, selecionados por baixa acuidade visual, correspondendo a $39,4 \%$ destes.

2. As variáveis idade, sexo, fato de residir na periferia, menarca, consulta oftalmológica prévia e uso anterior de correção não apresentaram correlação com a presença de miopia nesta amostra. 
Anexos 


\section{Anexo 1.}

Oficio $n^{\circ} 1513 / 2007$

$\mathrm{CEP} / \mathrm{SPC}$

Prezado Professor,

O trabalho intitulado "ESTUDO SOBRE A PREVALÊNCIA DE MIOPIA EM INDIVÍdUOS DE 10 A 15 ANOS DE IDADE RESIDENTES NA CIDADE DE GURUPI, TOCANTINS", foi analisado pelo Comitê de Ética em Pesquisa, em sua $246^{a}$ Reuniẫo Ordinária realizada em 07/05/2007, e enquadrado na categoria: APROVADO, bem como o Termo de Consentimento Livre e Esclarecido, de acordo com o Processo HCRP n² 2766/2007.

Atenciosamente.

Senhor

PROF. DR. JAYTER SILVA DE PAULA

FUAD MORAES IBRAHIM (Orientando)

Depto. de Oftalmo, Otorrino e Cirurgia de Cabeça e Pescoço

Comitê de Ética em Pesquisa HC e FMRP-USP - Campus Universitário FWA - 0000 2733; IRB - 00002186

Fone (16) 3602-2228 - E-mail : cepa herp. fimrp. usp. br

Monte Alegre 14048-900 Ribeirão Preto SP 
Anexo 2.

Estudo da prevalência de miopia em indivíduos de 10 a 15 anos em Gurupi TO

\title{
TERMO DE CONSENTIMENTO LIVRE E ESCLARECIDO
}

\author{
ESCLARECIMENTO AOS SUJEITOS DE PESQUISA E RESPONSÁVEIS
}

Prezado responsável

A miopia é o principal causa de deficiência visual que afeta indivíduos na faixa de idade de 10 a 15 anos. Este problema pode ser corrigido com o uso de óculos. Assim sendo, nós estamos realizando uma pesquisa na cidade de Gurupi para tentar identificar as pessoas que apresentam este tipo de doença, para que possam ser devidamente tratadas. As informações obtidas nesta pesquisa poderão ser úteis na criação de programas de busca e tratamento precoce deste tipo de doença.

A pesquisa é GRATUITA. O exame inicial será realizado em sua própria residência por uma equipe treinada, através do teste da visão para longe. Caso seja necessária uma avaliação mais detalhada, o individuo será encaminhado para exames GRATUITOS em uma clínica oftalmológica na cidade de Gurupi. Esclarecemos que esse exame não lhe trará nenhum desconforto e que não será necessário o uso de nenhuma medicação.

A participação nesta pesquisa é VOLUNTÁRIA, não sendo obrigatória a participação. As informações pessoais dos participantes são SECRETAS (mantendo total privacidade) e não serão divulgados dados que possam identificar os participantes. Além disso, nos compromissamos a prestar informações ou esclarecimentos atualizados durante todas as fases do estudo, mesmo que esses possam afetar a sua vontade de continuar participando. Caso concorde em participar, poderá também desistir em qualquer momento da pesquisa.

As pessoas que apresentarem visão menor do que a esperada serão encaminhadas para uma consulta oftalmológica GRATUITA na clínica LUMINA, AV Amazonas, 1457 tel. 33122444 para investigação.

PACIENTE:

RESPONSÁVEL LEGAL:

PESQUISADOR: Fuad Moraes Ibrahim

MÉDICO OFTALMOLOGISTA ～CRM TO 1578

AV Amazonas n 1457 TEL 6333122444

DATA: 
Anexo 3.

PROTOCOLO DE COLETA DE CAMPO

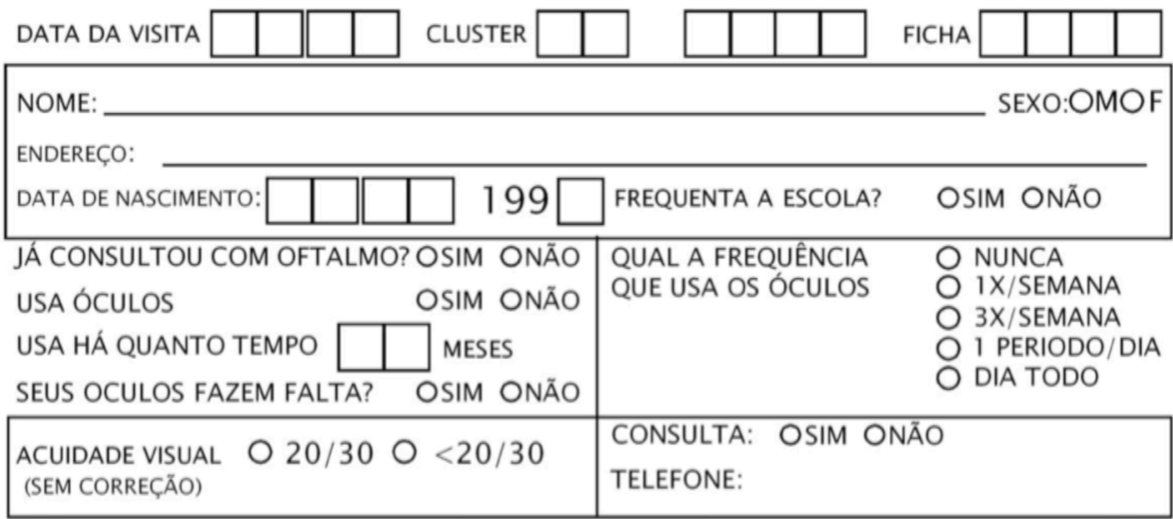

EXAMINADOR:

PROTOCOLO DE COLETA DE CAMPO

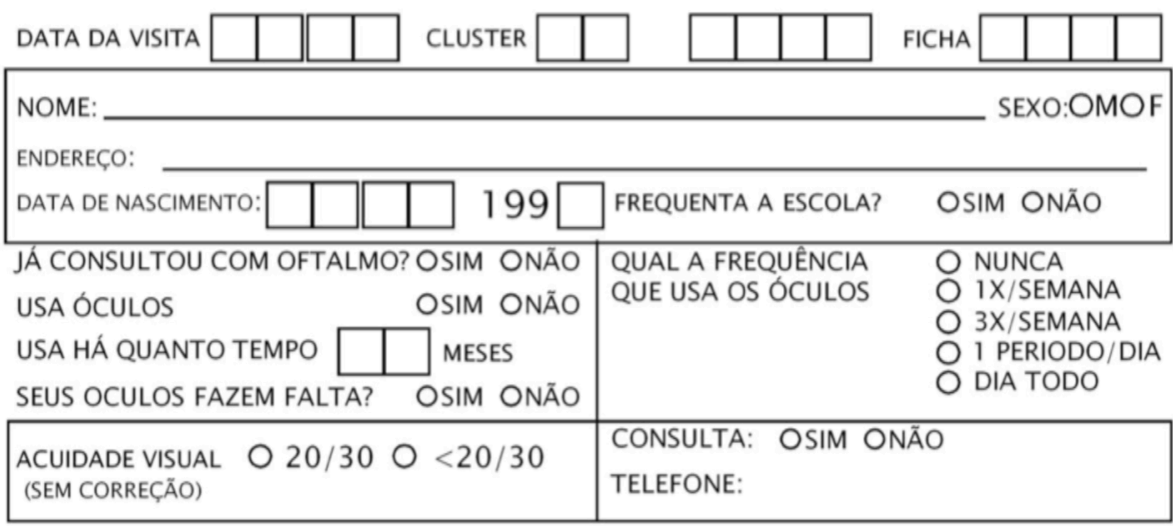

EXAMINADOR: 


\section{Anexo 4}

Estudo da prevalência de miopia em indivíduos de 10 a 15 anos em Gurupi TO

\section{TERMO DE CONSENTIMENTO LIVRE E ESCLARECIDO}

\section{ESCLARECIMENTO AOS SUJEITOS DE PESQUISA E RESPONSÁVEIS}

Prezado responsável

A miopia é o principal causa de deficiência visual que afeta indivíduos na faixa de idade de 10 a 15 anos. Este problema pode ser corrigido com o uso de óculos. Assim sendo, nós estamos realizando uma pesquisa na cidade de Gurupi para tentar identificar as pessoas que apresentam este tipo de alteração para que possam ser tratadas. As informações obtidas nesta pesquisa poderão ser úteis na criação de programas de busca e tratamento precoce deste tipo de alteração.

A pesquisa é GRATUITA. Após avaliação pela equipe, a pessoa avaliada apresentou visão menor que a esperada para a sua idade. Em função disto, será necessária a realização de alguns exames para que possa ser determinada a causa desta alteração. Todos os exames serão feitos GRATUITAMENTE.

Para a realização destes exames é necessário o uso de um colírio cicloplégico, que irá dilatar a pupila e atrapalhar a visão para perto por aproximadamente SEIS horas (variando de pessoa para pessoa). Este poderá ser o principal desconforto causado pelo exame. Os pacientes que necessitarem de óculos receberão a receita com o grau para a confecção destes. Caso necessitem de acompanhamento ou tratamento especializado, por motivos de outros problemas oculares, serão devidamente encaminhados para serviço de referência.

A participação nesta pesquisa é VOLUNTÁRIA. As informações pessoais dos participantes são SECRETAS (mantendo total privacidade) e não serão divulgados dados que possam identificar os participantes. Além disso, nós assumimos o compromisso de prestar informações ou esclarecimentos atualizados durante todas as fases do estudo, mesmo que esses possam afetar a sua vontade de continuar participando. Caso NÃO concorde em continuar participando, poderá desistir em qualquer momento da pesquisa.

RESPONSÁVEL LEGAL:

PACIENTE:

Fuad Moraes Ibrahim

CRM TO 1578

AV Amazonas n 1457 TEL 6333123833

DATA: 
Anexo 5.

PROTOCOLO DE COLETA DO CONSULTÓRIO

\begin{tabular}{|c|c|c|c|c|c|c|c|c|c|c|}
\hline DATA DA CONSULTA & & CLUSTER & & CASO & & & FICHA & & & \\
\hline NOME: & & & & & \multicolumn{2}{|c|}{ IDADE } & & \multicolumn{3}{|c|}{ SEXO:OMOF } \\
\hline ÓCULOS OD & & ESF - & $\mathrm{CIL}$ & & \multicolumn{2}{|r|}{ EIXO } & AV & $20 /$ & & \\
\hline OSIM ONÃO OE & & ESF - & CIL & & \multicolumn{2}{|r|}{ EIXO } & AV & $20 /[$ & & \\
\hline $\begin{array}{l}\text { TEMPO DE } \\
\text { USO ÓCULOS }\end{array}$ & MESES & $\begin{array}{l}\text { MOTILIDADE } \\
\text { OCULAR }\end{array}$ & OORT & T OXT & OET & \multicolumn{2}{|c|}{ MENARCA } & OS & & ONÄO \\
\hline \multirow[t]{2}{*}{ REFRAÇÃO OD - } & & ESF - & $\mathrm{CIL}$ & & & EIXO & AV & $20 /$ & & \\
\hline & & ESF - & $\mathrm{CIL}$ & & & EIXO & AV & $20 /[$ & & \\
\hline
\end{tabular}

CAUSAS DE BAIXA DE VISÃO

OTRACOMA OOPACIDADES DE CÓRNEA OCATARATA OALTERAÇŐES DE RETINA OAMBLIOPIA OOUTRAS

PROTOCOLO DE COLETA DO CONSULTÓRIO

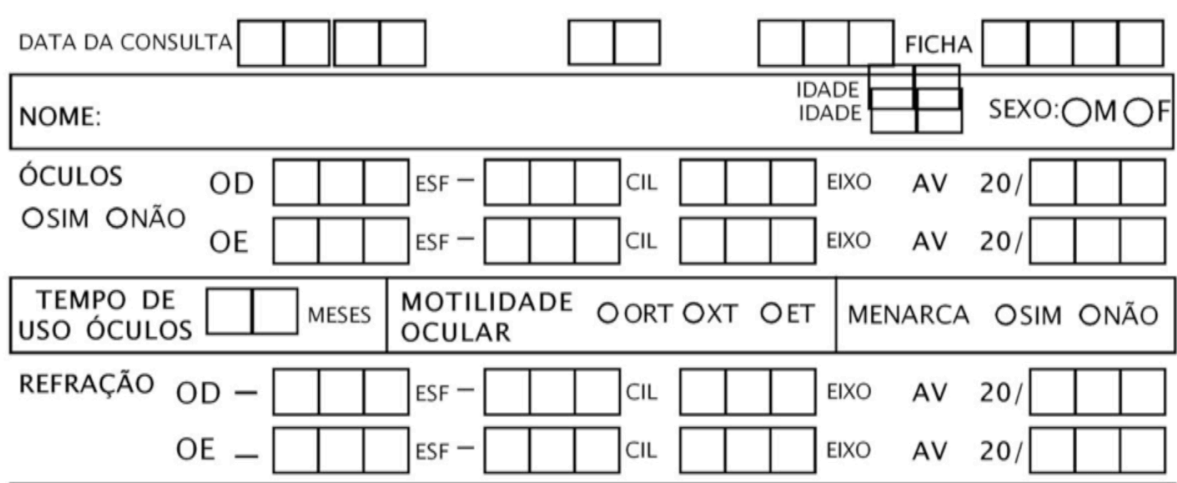

CAUSAS DE BAIXA DE VISÃO

OTRACOMA OOPACIDADES DE CÓRNEA OCATARATA OALTERAÇŌES DE RETINA OAMBLIOPIA OOUTRAS 
Anexo 6.

Tabela 5. Distribuição do astigmatismo dos sujeitos examinados no consultório.

\begin{tabular}{lll}
\hline Cilíndro (dioptrias) & Olho direito & Olho esquerdo \\
\hline$<0,75$ & 36 & 30 \\
$\geq 0,75$ a $<2,00$ & 18 & 23 \\
$\geq 2,00$ & 11 & 12 \\
\hline
\end{tabular}


Referências 
Albuquerque, A. D., Ed. Refração: Cultura Médica, 4 ed. 2005.

Ayed, T., M. Sokkah, et al. Epidemiologic study of refractive errors in schoolchildren in socioeconomically deprived regions in Tunisia. J Fr Ophtalmol, v.25, n.7, Sep, p.712-7. 2002.

Bicas, H. Oftalmologia: fundamentos. 1991. 140-141 p.

Refratometria Ocular, v.1. 2005 (Conselho Brasileiro de Oftalmologia)

Cernea, P., F. Constantin, et al. [Genetic aspects of myopia]. Rev Med Chir Soc Med Nat Iasi, v.77, n.4, Oct-Dec, p.727-32. 1973.

Chuka-Okosa, C. M. Refractive errors among students of a postprimary institution in a rural community in south-eastern Nigeria. West Afr J Med, v.24, n.1, Jan-Mar, p.62-5. 2005.

Conde, H. Prevenção da cegueira no Brasil; métodos e afins. Arq Bras Oftalmol, v.2, 1940, p.271-276. 1940.

Dandona, R., L. Dandona, et al. Refractive error in children in a rural population in India. Invest Ophthalmol Vis Sci, v.43, n.3, Mar, p.615-22. 2002.

Donoso, R. e P. Castillo. Correction of high myopia with the PRL phakic intraocular lens. J Cataract Refract Surg, v.32, n.8, Aug, p.1296-300. 2006.

Dre. Relatório de evasão escolar na cidade de Gurupi - TO. Delegacia Estadual da Eduacação. Gurupi. 2007

Duke-Elder`S, Ed. Refração Prática: REVINTER, p.306, 10 ed. 1997.

El-Bayoumy, B. M., A. Saad, et al. Prevalence of refractive error and low vision among schoolchildren in Cairo. East Mediterr Health J, v.13, n.3, May-Jun, p.575-9. 2007.

Estaica, P. Prevalência de erros refrativos em escolares da primeira série do ensino fundamental

da região Nordeste do Rio Grande do Sul. Rev Bras Oftalmol, v.66, n.5, p.297-303. 2007.

Fan, D. S., D. S. Lam, et al. Prevalence, incidence, and progression of myopia of school children in Hong Kong. Invest Ophthalmol Vis Sci, v.45, n.4, Apr, p.1071-5. 2004.

Farbrother, J. E., G. Kirov, et al. Linkage analysis of the genetic loci for high myopia on $18 \mathrm{p}, 12 \mathrm{q}$, and $17 \mathrm{q}$ in 51 U.K. families. Invest Ophthalmol Vis Sci, v.45, n.9, Sep, p.2879-85. 2004.

Firmo, G. Prevalência de afecções oculares em escolares da zona sul do munícipio de São Paulo. Arq Bras Oftalmol, v.62, n.4, p.444f. 1997. 
Fotedar, R., E. Rochtchina, et al. Necessity of cycloplegia for assessing refractive error in 12-year-old children: a population-based study. Am J Ophthalmol, v.144, n.2, Aug, p.307-9. 2007.

Fotouhi, A., H. Hashemi, et al. The prevalence of refractive errors among schoolchildren in Dezful, Iran. Br J Ophthalmol, v.91, n.3, Mar, p.287-92. 2007.

Garcia, C. A., F. Orefice, et al. Prevalence of refractive errors in students in Northeastern Brazil. Arq Bras Oftalmol, v.68, n.3, May-Jun, p.321-5. 2005.

Gilbert, C. E. e L. B. Ellwein. Prevalence and causes of functional low vision in schoolage children: results from standardized population surveys in Asia, Africa, and Latin America. Invest Ophthalmol Vis Sci, v.49, n.3, Mar, p.877-81. 2008.

Goh, P. P., Y. Abqariyah, et al. Refractive error and visual impairment in school-age children in Gombak District, Malaysia. Ophthalmology, v.112, n.4, Apr, p.678-85. 2005.

Goldschmidt, E. The mystery of myopia. Acta Ophthalmol Scand, v.81, n.5, Oct, p.4316. 2003.

Group, R. E. W. Report on strategic planning meeting of Refractive Error Working Group. REWG Meeting. Sydney, 2002. p.

Hatakeyama, S. Vício de refração em escolares do distrito ferederal, Brasil no ano de 1985. Arq Bras Oftalmol, v.52, n.4, p.145f. 1985.

He, M., W. Huang, et al. Refractive error and visual impairment in school children in rural southern China. Ophthalmology, v.114, n.2, Feb, p.374-82. 2007.

Heng, L. S. e C. Y. Khoo. Can contact lenses control the progression of myopia? Singapore Med J, v.35, n.4, Aug, p.367-70. 1994.

Ip, J. M., S. M. Saw, et al. Role of near work in myopia: findings in a sample of Australian school children. Invest Ophthalmol Vis Sci, v.49, n.7, Jul, p.2903-10. 2008.

Junghans, B., P. M. Kiely, et al. Referral rates for a functional vision screening among a large cosmopolitan sample of Australian children. Ophthalmic Physiol Opt, v.22, n.1, Jan, p.10-25. 2002.

Junghans, B. M. e S. G. Crewther. Prevalence of myopia among primary school children in eastern Sydney. Clin Exp Optom, v.86, n.5, Sep, p.339-45. 2003.

Kara-Jose, N. Criação do núcleo de prevenção à cegueira. Arq Bras Oftalmol, v.50, n.4, 1982, p.145-7. 1982.

Kara-Jose, N. G., E.R.; Carvalho, R. S. . Olho no Olho. Rio de Janeiro. 2006. 182 p. $(\mathrm{CBO})$ 
Kawuma, M. e R. Mayeku. A survey of the prevalence of refractive errors among children in lower primary schools in Kampala district. Afr Health Sci, v.2, n.2, Aug, p.69-72. 2002.

Khader, Y. S., W. Q. Batayha, et al. Prevalence and risk indicators of myopia among schoolchildren in Amman, Jordan. East Mediterr Health J, v.12, n.3-4, May-Jul, p.4349. 2006.

Khandekar, R., P. Kurup, et al. Determinants of the progress of myopia among Omani school children: a historical cohort study. Eur J Ophthalmol, v.17, n.1, Jan-Feb, p.110-6. 2007.

Krachmer, J. H. CORNEA, v.2. 2005. 2086 p.

Loman, J., G. E. Quinn, et al. Darkness and near work: myopia and its progression in third-year law students. Ophthalmology, v.109, n.5, May, p.1032-8. 2002.

Maul, E., S. Barroso, et al. Refractive Error Study in Children: results from La Florida, Chile. Am J Ophthalmol, v.129, n.4, Apr, p.445-54. 2000.

Mavracanas, T. A., A. Mandalos, et al. Prevalence of myopia in a sample of Greek students. Acta Ophthalmol Scand, v.78, n.6, Dec, p.656-9. 2000.

Murthy, G. V., S. K. Gupta, et al. Refractive error in children in an urban population in New Delhi. Invest Ophthalmol Vis Sci, v.43, n.3, Mar, p.623-31. 2002.

Muszynska-Lachota, I., D. Czepita, et al. Prevalence of refractive errors in 7 and 8 yearold children in the province of Western Pomerania. Ann Acad Med Stetin, v.51 Suppl 1, p.109-11. 2005.

Mutti, D. O., M. E. Cooper, et al. Candidate gene and locus analysis of myopia. Mol Vis, v.13, p.1012-9. 2007.

Mutti, D. O., G. L. Mitchell, et al. Parental myopia, near work, school achievement, and children's refractive error. Invest Ophthalmol Vis Sci, v.43, n.12, Dec, p.3633-40. 2002.

Naidoo, K. S., A. Raghunandan, et al. Refractive error and visual impairment in African children in South Africa. Invest Ophthalmol Vis Sci, v.44, n.9, Sep, p.3764-70. 2003.

Negrel, A. D., E. Maul, et al. Refractive Error Study in Children: sampling and measurement methods for a multi-country survey. Am J Ophthalmol, v.129, n.4, Apr, p.421-6. 2000.

Pokharel, G. P., A. D. Negrel, et al. Refractive Error Study in Children: results from Mechi Zone, Nepal. Am J Ophthalmol, v.129, n.4, Apr, p.436-44. 2000.

Robaei, D., K. Rose, et al. Patterns of spectacle use in young Australian school children: findings from a population-based study. J Aapos, v.9, n.6, Dec, p.579-83. 2005. 
Rose, K. A., I. G. Morgan, et al. Outdoor activity reduces the prevalence of myopia in children. Ophthalmology, v.115, n.8, Aug, p.1279-85. 2008.

. Myopia, lifestyle, and schooling in students of Chinese ethnicity in Singapore and Sydney. Arch Ophthalmol, v.126, n.4, Apr, p.527-30. 2008.

Salomao, S. R. PREVALENCE AND CAUSES OF VISUAL IMPAIRMENT IN LOWMIDDLE

INCOME SCHOOL CHILDREN IN SÃO PAULO, BRAZIL. in press. 2008.

Saw, S. M., L. Tong, et al. Incidence and progression of myopia in Singaporean school children. Invest Ophthalmol Vis Sci, v.46, n.1, Jan, p.51-7. 2005.

Schimiti, R. Prevalência de afecções oculares em pré-escolares e escolares no município de Ibiporão - PR - BR. Arq Bras Oftalmol, v.60, n.4, p.404. 2001.

Ventura, L. E. A. Importância da valorização da queixa principal das crianças e adolescentes de famílias de baixa renda da periferia da cidade de Recife-PE. Arq Bras Oftalmol, v.4. 1997.

Villarreal, G. M., J. Ohlsson, et al. Prevalence of myopia among 12- to 13-year-old schoolchildren in northern Mexico. Optom Vis Sci, v.80, n.5, May, p.369-73. 2003.

Villarreal, M. G., J. Ohlsson, et al. Myopisation: the refractive tendency in teenagers. Prevalence of myopia among young teenagers in Sweden. Acta Ophthalmol Scand, v.78, n.2, Apr, p.177-81. 2000.

Vision2020. The Right to Sight 2008.

Visioncenter. 2008.

Wallman, J. Parental history and myopia: taking the long view. JAMA, v.272, n.16, Oct 26, p.1255-6. 1994.

Wedner, S. H., D. A. Ross, et al. Myopia in secondary school students in Mwanza City, Tanzania: the need for a national screening programme. Br J Ophthalmol, v.86, n.11, Nov, p.1200-6. 2002.

Who, W. H. O. Magnitude and causes of visual impairment 2007.

Wikipedia. Gurupi 2007.

Yanoff, M. D., J. S. Ophthalmology: Mosby, v.1. 2004. 1650 p.

Zhao, J., X. Pan, et al. Refractive Error Study in Children: results from Shunyi District, China. Am J Ophthalmol, v.129, n.4, Apr, p.427-35. 2000. 